\title{
Heat-treated optimized polysulfone electrospun nanofibrous membranes for high performance wastewater microfiltration
}

\author{
P. Arribas ${ }^{\mathrm{a}, \mathrm{b}, *}$, M.C. García-Payo ${ }^{\mathrm{b}}$, M. Khayet ${ }^{\mathrm{b}, \mathrm{c}, *}$, L. Gil ${ }^{\mathrm{d}}$ \\ ${ }^{\text {a }}$ Campus of International Excellence, Moncloa Campus (UCM-UPM), Madrid, Spain \\ ${ }^{\mathrm{b}}$ Department of Structure of Matter, Thermal Physics and Electronics, Faculty of Physics, University Complutense of Madrid, Avda. Complutense s/n, 28040 Madrid, Spain \\ ${ }^{\mathrm{c}}$ Madrid Institute for Advanced Studies of Water (IMDEA Water Institute), Calle Punto Net $N^{\circ}$ 4, 28805, Alcalá de Henares, Madrid, Spain \\ ${ }^{\mathrm{d}}$ Genetics and Eco-Physiology Research Group, School of Forest Engineering, University Polytechnic of Madrid, Avda. Complutense s/ $n$, 28040 Madrid, Spain
}

\section{A R T I C L E I N F O}

\section{Keywords:}

Nanofiber

Heat post-treatment

Electrospun membrane

Humic acid

Microfiltration

\begin{abstract}
A B S T R A C T
The structure and morphology of self-sustained electrospun nanofibrous membranes (ENMs) are key factors determining membrane performance for filtration applications. In this study, heat post-treatment (HPT) method was applied to modify the structural and morphological properties of polysulfone (PSU) ENMs, to improve their filtration performance and to obtain membranes suitable for wastewater treatment. The influence of the HPT temperature and time on the morphological structure of the PSU ENMs as well as on fouling and filtration performance was investigated. Microfiltration (MF) tests were conducted using humic acid model solutions with a concentration of $15 \mathrm{mg} / \mathrm{L}$ at $\mathrm{pH}$ 11. Increasing the HPT temperature or time, led to an increase of the mean nanofiber diameter along with a decrease of the mean size of the inter-fiber space, the void volume fraction and the water contact angle of the membranes. ENMs treated with a higher HPT temperature and a longer time exhibited higher nanofibers interconnectivity and a more compact structure with a smaller size of inter-fiber spaces. Under the same MF operating conditions, a commercial polyethersulfone (PES) MF membrane (HPWP, Millipore) had lower filtration performance (i.e. lower performance index, $P I, 82 \mathrm{~kg} / \mathrm{m}^{2} \mathrm{~h}$ ) than the treatedoptimized PSU ENMs (i.e. 147 and $133 \mathrm{~kg} / \mathrm{m}^{2} \mathrm{~h}$ for ENMs 9 and 10, respectively). The obtained results confirm the good performance of the developed PSU ENMs for MF applications.
\end{abstract}

\section{Introduction}

The development of efficient membrane filtration technologies is especially important as water shortage has become a growing global problem in recent years [1]. The improved compactness, low cost operation, high energy efficiency and high throughput enable membrane separation processes to compete successfully with conventional separation processes. In fact, membranes are an environmentally-friendly method highly utilized in waste treatment, water purification and in clarification and concentration processes [2]. However, the fabrication of adequately designed membranes for a specific application is challenging [3]. Electrospinning is an attractive and efficient technique for polymer solution processing that provides a simple and versatile way to prepare ultrafine polymeric fibers with micro- to nano-scale diameters, ranging from $50 \mathrm{~nm}$ to $10 \mu \mathrm{m}$ thickness [4,5]. Electrospun fibers are typically collected in the form of a non-woven mesh, which is of importance for a variety of applications including semi-permeable membranes, filters, composite reinforcement and scaffolding used in tissue engineering [6]. Electrospun nanofibrous membranes (ENMs) have a great potential for membrane filtration due to their attractive structural features, such as high porosity and interconnected open pore structure, micro-scale interstitial space, controllable thickness and a large surface area to volume ratio [7]. In ENMs the pores are induced by the entanglement of interconnected nanofibers (i.e. inter-fiber space). The mean pore size of ENMs correlates with the nanofiber diameter [8]. Thus, the pore size of ENMs can be tuned to meet different filtration requirements by changing the nanofiber diameter.

Advantages of using ENMs for water treatment include high permeability, mainly related to their high void volume fraction (i.e. porosity), and good separation factor due to the highly tortuous path through the nanofibrous structure and the remaining static charge in the nanofibers after electrospinning, which helps to separate different contaminants [9-11]. In recent years, microfiltration (MF) has attracted increasing attention in the field of wastewater treatment and

\footnotetext{
*Corresponding authors at: Department of Structure of Matter, Thermal Physics and Electronics, Faculty of Physics, University Complutense of Madrid, Avda. Complutense s/n, 28040 Madrid, Spain.

E-mail addresses: paulaarribas@ucm.es (P. Arribas), khayetm@fis.ucm.es (M. Khayet).
} 
reclamation as an alternative to conventional water treatment processes (i.e. coagulation, sedimentation and sand filtration) [12]. MF offers several advantages including easier control of operation, and reduced maintenance and sludge production. However, a major factor that limits the use of membranes in water treatment is membrane fouling, which reduces water production rates and increases energy consumption [13]. Fouling reduces the effective membrane surface for filtration leading to a strong decline of permeate flux and worse separation performance $[7,14,15]$. Given that membrane properties have a high impact on fouling, it is important to understand their effects well in order to develop adequate membranes that are capable to mitigate fouling. For instance, it has been demonstrated that membrane hydrophobicity, roughness, pore size and pore morphology affect membranefoulant-interactions and consequently, fouling effects [16].

In the literature, there is a large number of studies using nanofibrous scaffolds or ENMs as pre-filters for particulate removal through MF/UF applications. Some of the most mentioned drawbacks of ENMs are the low mechanical strength and the difficulty of handling them after electrospinning [17]. Several methods were proposed to overcome these problems before their application in filtration: plasticization [18]; polymer blending [19]; solvent induced inter-nanofiber bonding [9]; hot-pressing [20-22]; heat treatment [5-7,23-26]; addition of nanoparticles [27,28]; use of crosslinking agents [29]. One of the most effective approaches is to enhance the bonding at junction points in the nanofiber mat by welding the nanofibers together, as for example by applying a heat post-treatment (HPT) (i.e. heating the mat between the glass transition temperature of the electrospun polymer and its melting temperature). Compared to plasticizing and polymer blending, an appropriate heat treatment may be more environmental friendly and less energy consuming. The incorporation of nanoparticles in the membrane matrix, such as titanium dioxide, usually needs a post-treatment of the membrane (e.g. hydrothermal bath, annealing), which increases the membrane fabrication costs [27]. Moreover, although hot-pressing has been reported to increase the structural integrity and mechanical strength of the ENMs, heat treatment can also induce a change in the molecular structure of the polymer, leading to a higher degree of nanofibers crystallinity [30] and, consequently, to a greater elastic modulus of the ENMs $[2,23]$.

In this study, the filtration properties of polysulfone electrospun nanofibrous membranes (PSU ENMs) were improved by the application of HPT. The effects of the HPT temperature and the HPT time on the structural and morphological properties of the membranes (i.e. porosity, pore size and its distribution, wettability, thickness) were investigated, because these factors affect the membrane filtration performance $[2,31]$. The filtration performance index $(P I)$ was considered to select the optimum heating conditions for the application of the ENMs in wastewater treatment by MF.

\section{Materials and methods}

\subsection{Materials}

The polymer polysulfone (PSU, UDEL P-3500 LCD, Solvay Specialty Polymers; $M_{w}=79,000 \mathrm{~g} / \mathrm{mol} ; \rho=1.24 \mathrm{~g} / \mathrm{cm}^{3}$ ) and the mixture of solvents N, N-dimethyl formamide (DMF, Sigma-Aldrich) and tetrahydrofuran (THF, Sigma-Aldrich) were used to prepare the spinning solution. The organic foulant humic acid (HA, Fluka) with a molecular weight of $4.1 \mathrm{kDa}$ was utilized to prepare the feed solution for the MF tests. Sodium hydroxide $(\mathrm{NaOH}$, Panreac) was used to prepare a concentrated HA stock solution of $1 \mathrm{~g} / \mathrm{L}$. Hydrochloric acid ( $\mathrm{HCl}$, Sigma-Aldrich) was employed to adjust the $\mathrm{pH}$ of the diluted HA feed solutions $(15 \mathrm{mg} / \mathrm{L})$ to 11. Isopropyl alcohol (IPA, Sigma-Aldrich) was used to determine the void volume fraction $(\varepsilon)$ of the PSU ENMs. POREFIL ${ }^{\circledR}$, a fluorinated hydrocarbon (chemical nature: pefluoroether; surface tension: $16 \mathrm{mN} / \mathrm{m}$, vapor pressure: $3.33 \mathrm{~Pa}$; viscosity: $4.4 \mathrm{mPa}$, POROMETER) was used as a wetting liquid to perform the inter-fiber space measurements.

\subsection{Preparation and characterization of the polymer solution}

The polymer solution was prepared by mixing DMF (64 wt $\%$ ) and THF (16 wt\%) at room temperature with a magnetic stirrer (IKA, RCT basic) for $2 \mathrm{~min}$ at $80 \mathrm{rpm}$. Subsequently, $20 \mathrm{wt} \% \mathrm{PSU}$ was added to the solvent mixture and the solution was stirred at $60^{\circ} \mathrm{C}$ and $80 \mathrm{rpm}$ for $10 \mathrm{~h}$ until the PSU was completely dissolved and the resulting polymer solution homogeneous.

The polymer solution was characterized by measuring its surface tension, viscosity and electrical conductivity. The surface tension of the spinning solution was determined at room temperature by the pendant drop shape analysis using an Optical Contact Angle Meter (CAM 200) and a stainless steel needle with an outer diameter of $1.825 \mathrm{~mm}$. The volume of all drops was maintained constant at $16.08 \pm 0.82 \mu \mathrm{L}$. The viscosity of the spinning solution was measured with a Digital Viscometer (Brookfield, Model DV-I+) in a cylindrical sample container and using the SC4-31 spindle at $30 \mathrm{rpm}$ and a shear rate of $10.2 \mathrm{~s}^{-1}$. The temperature of the spinning solution was maintained constant at $25^{\circ} \mathrm{C}$ by a thermostat (Techne, Model TU-16D). The electrical conductivity of the polymer solution was measured at $25^{\circ} \mathrm{C}$ using a conductivity meter (CyberScan con 11 Conductivity/TDS $/{ }^{\circ} \mathrm{C}$, Eutech Instruments).

\subsection{Preparation of PSU ENMs}

PSU ENMs were prepared by electrospinning using the polymer solution indicated in the previous section. The used electrospinning system was described elsewhere [7]. In this study, all PSU ENMs were prepared under the previously obtained optimum electrospinning parameter conditions: a polymer solution flow rate of $2.5 \mathrm{~mL} / \mathrm{h}$, an electric voltage of $16 \mathrm{kV}$, a distance between the needle tip and the collector or air gap of $10 \mathrm{~cm}$ and an electrospinning time of $45 \mathrm{~min}$ [7]. The ambient conditions during electrospinning fabrication were a temperature between 20 and $25^{\circ} \mathrm{C}$ and a relative humidity in the range $38-41 \%$.

\subsection{Heat post-treatment (HPT) of PSU ENMs}

The silky, fluffy and loose structure of the PSU ENMs complicated their handling after the electrospinning step. In addition, it was observed that PSU ENMs without any HPT were not useful for filtration application as the membranes were not capable to achieve any separation. Thus, a HPT step was carried out to get membranes with improved structural integrity and greater filtration performance.

The HPT was carried out in a ceramic oven (CWF 13/13, Carbolite ${ }^{\circledast}$ ). Before being placed into the oven, the ENMs deposited on the aluminum foil were attached to a smaller rounded copper support to avoid shrinkage of the membrane during heating. The samples were first heated from $70{ }^{\circ} \mathrm{C}$ to the established HPT temperature (i.e. $190-250{ }^{\circ} \mathrm{C}$ ) at a rate of $30^{\circ} \mathrm{C} / \mathrm{min}$ (this process took between 6 and $8 \mathrm{~min}$, depending on the final temperature) and then exposed to the HPT temperature for a specific HPT time (i.e. 20-300 min). HPT temperatures above the boiling point of the used solvents were chosen to guarantee their complete evaporation from the formed ENMs. To induce good bonding points between nanofibers (i.e. points in which nanofibers were fused together) the applied temperatures were also higher than the glass transition temperature of the used polymer $\left(185^{\circ} \mathrm{C}\right.$ for PSU). After the HPT step, ENMs were wetted with DI water, peeled off from the aluminum foil, dried at room temperature for $24 \mathrm{~h}$ and stored until use.

In order to perform a systematic and accurate study on the effect of the HPT on the morphological structure of PSU ENMs, all membranes were obtained from the same manufacturing batch, avoiding as many steric dissimilarities (in terms of, for example, pore size, structure, porosity and surface roughness) between them as possible. In addition, SEM images of membranes with an initial thickness of $900 \pm 50 \mu \mathrm{m}$ 
were used to select those ENMs with similar initial nanofibrous structure (i.e. uniformity of the nanofiber web).

It was observed that not all the heat post-treatments (HPTs) led to the same morphology and structure of the membranes. In order to fully understand the influence of the applied HPT on the morphological and structural changes of PSU ENMs, a preliminary study with 90 membranes and 30 different HPTs was conducted to determine the operational working area (i.e. region of interest) of the HPT as shown later on. Then, a systematic study in this region of interest was conducted and eleven PSU ENMs were evaluated and compared in terms of their morphological characteristics (i.e. mean nanofiber diameter, mean size of the inter-fiber space, water contact angle, void volume fraction, etc.). Moreover, MF tests were carried out with these eleven ENMs to determine the optimum region of the HPT, in which the treated membranes exhibit the highest filtration performance indexes.

\subsection{Characterization of PSU ENMs}

The thickness of each PSU ENM was measured at 40 different spots on the sample using a micrometer equipped with a feeler (ISL Isocontrol). The final thickness of each sample was determined as the average value of the measured thicknesses with its corresponding standard deviation.

The morphology of the surface of the PSU ENMs was evaluated with a field emission scanning electron microscope (FESEM, JEOL Model JSM-6335F) operating at $5 \mathrm{kV}$. Before conducting the SEM analysis, a thin gold layer of approximately $5 \mathrm{~nm}$ was sputter-coated on the membrane surface using an evaporator (EMITECH K550 X) for one minute under $25 \mathrm{~mA}$. SEM images were analyzed with the UTHSCSA Image Tool 3.0 software to determine the nanofiber diameter. For each membrane, at least three SEM images were analyzed and the diameters of a total number of 100 nanofibers/per image were measured. Statistical analyses were applied to determine the nanofiber diameter distribution (i.e. nanofiber diameter histogram). The weighted arithmetic mean of the nanofiber diameters $\left(\lambda_{w}\right)$ along with its corresponding weighted standard deviation $\left(s_{w}\right)$ were evaluated as follows:

$\lambda_{w}=\lambda_{0}+\frac{h}{N} \sum_{j=1}^{m} u_{j} \cdot F C_{j}$

$s_{w}=\sqrt{\left(\frac{1}{N} \sum_{j=1}^{m}\left(u_{j}^{2} \cdot F C_{j}\right)-\left(\frac{1}{N} \sum_{j=1}^{m}\left(u_{j} \cdot F C_{j}\right)\right)^{2}\right) \cdot h^{2}}$

where $m$ denotes de number of bins (disjoint categories), $h$ is the width, $h=\left(\lambda_{\max }-\lambda_{\min }\right) / m, F C$ is the frequency count, $N$ is the number of samples in the statistical set (in our case $N=100$ ), $\lambda_{0}$ is the dominant characteristic of the statistical set that corresponds to the highest peak, $u$ is a variable defined as $u=\left(\lambda_{c}-\lambda_{0}\right) / h$ and $\lambda_{c}$ is the bin characteristic (or bin center).

The final value of the weighted arithmetic mean of the nanofiber diameters $\left(\lambda_{w}^{-}\right)$with its corresponding weighted standard deviation $\left(s_{w}^{-}\right)$ for the PSU ENMs was determined as the arithmetic mean and standard deviation of all SEM samples evaluated for each membrane.

The water contact angle $\left(\theta_{w}\right)$ values on the surface of the PSU ENMs were measured at room temperature using a computerized optical system (CAM100 device, Sb) equipped with a CCD camera and an image analysis software (Cam200usb). This system enables the acquisition of photographs of the water drop on the sample surface and to evaluate the contact angle. A Hamilton stainless steel needle was used to control the volume of the drops, which was between 12 and $14 \mu \mathrm{L}$. Every drop was recorded taking five images within $4 \mathrm{~s}$. For each ENM sample at least 10 different drops were considered to determine the final averaged $\theta_{w}$ value together with its standard deviation.

The void volume fraction (i.e. porosity, $\varepsilon$ ) is defined as the ratio between the volume of the inter-fiber space and the total volume of the membrane. The value of $\varepsilon$ was determined by measuring the density of the polymer material $\left(\rho_{p o l}\right)$ using isopropyl alcohol (IPA), which penetrates inside the inter-fiber space, and the density of the membrane $\left(\rho_{m}\right)$ using distilled water, which does not get into the inter-fiber space, according to Eq. (3) [32]:

$\varepsilon(\%)=\left(1-\frac{\rho_{m}}{\rho_{p o l}}\right) \cdot 100$

The inter-fiber space $\left(d_{f}\right)$ of the PSU ENMs was measured with capillary flow porometry (CFP) using a gas-liquid displacement Porometer (POROLUX ${ }^{\mathrm{TM}} 100$, Porometer). CFP uses the displacement of a wetting liquid inside a porous network by means of an inert gas flow to measure $d_{\mathrm{f}}$. In this study, POREFIL ${ }^{\circledR}$ (Porometer) was used as the wetting liquid agent, compressed air was employed as the inert gas and the applied hydrostatic pressure was varied in the range of 0-0.7 MPa at room temperature $\left(\sim 23^{\circ} \mathrm{C}\right)$. The ENMs were first wetted by the POREFIL $^{\circledast}$ and the gas permeation flow was measured by increasing the transmembrane pressure to obtain the $S$ shaped wet curve. Subsequently, the dry curve was obtained by measuring the gas flow through the dry sample as a function of the applied pressure. Both, the wet and the dry curves were used to determine the mean size of the inter-fiber space $\left(\bar{d}_{\mathrm{f}}\right.$, which corresponds to the size of the inter-fiber space at which the wet curve intersects the half-dry curve that corresponds to $50 \%$ gas flow through the dry membrane), the inter-fiber space distribution or differential filter flow (DFF, which represents the increase in flow rate per unit increase in inter-fiber space), and the cumulative filter flow distribution (CFF, i.e. percentage of the total gas flow that goes through inter-fiber spaces of a certain size and larger) of the PSU EMNs.

\subsection{Filtration experiments}

The experimental set up used for MF tests was described elsewhere [7]. The effective filtration area of the membrane was $(21.76 \pm 0.01) \cdot 10^{-4} \mathrm{~m}^{2}$. The feed solution was kept at room temperature $\left(\sim 23^{\circ} \mathrm{C}\right)$ and the feed flow rate was maintained at $1.6-1.8 \mathrm{~L} /$ $\min$.

To carry out the MF tests, diluted HA feed solutions of $15 \mathrm{mg} / \mathrm{L}$ were prepared from a concentrated HA stock solution of $1 \mathrm{~g} / \mathrm{L}$. In our previous study, it was demonstrated that PSU ENMs were not selective to HA in acidic media $(\mathrm{pH}=3)$, whereas clear HA separation factors were observed when using alkaline HA solutions $(\mathrm{pH}=11)$ [7]. Thus, in this study the solution $\mathrm{pH}$ was adjusted to 11 by adding $2 \mathrm{M} \mathrm{NaOH}$ as needed using a pH/Ion meter (692, Metrohm). A spectrophotometer (UV/VIS 7315, Jenway) was used to determine the HA concentration of the permeate, the retentate and the feed samples at a wavelength of $254 \mathrm{~nm}$.

Before carrying out the MF tests, all membranes were pre-compacted by circulating distilled water at a transmembrane pressure $(\Delta P)$ of $3 \cdot 10^{5} \mathrm{~Pa}$ for $3 \mathrm{~h}$. Subsequently, MF tests were conducted at a transmembrane pressure of $10^{5} \mathrm{~Pa}$ using first distilled water for $1 \mathrm{~h}$ to determine the pure water permeability ( $P W P$ ), then the aqueous HA feed solution for $7 \mathrm{~h}$ (i.e. HA test), and finally distilled water again for $1 \mathrm{~h}$. The permeate fluxes of both HA solution $\left(J_{H A}\right)$ and distilled water before $\left(J_{w 0}\right)$ and after $\left(J_{w f}\right)$ each HA test were measured and the irreversible fouling factor $\left(F R_{W}\right)$ of the membrane was evaluated as follows [33]:

$F R_{W}(\%)=\frac{J_{w_{0}}-J_{w_{f}}}{J_{w 0}} \cdot 100$

The permeate fluxes were calculated using the weight of the permeate produced during a specific time on an electronic balance (AND GF-1200) as follows: 
$J\left(\frac{k g}{m^{2} h}\right)=\frac{m}{A_{e f} \Delta t}$

where $m$ is the mass of the obtained permeate over a period of time $\Delta t$, and $A_{e f}$ is the effective filtration membrane area.

The separation factor $(\alpha)$ of the membranes was evaluated using the following equation:

$\alpha(\%)=\left(1-\frac{2 C_{p}}{C_{r}+C_{f}}\right) \cdot 100$

where $C_{p}, C_{r}$ and $C_{f}$ are the HA concentration of the permeate, retentate and feed solutions, respectively.

The initial HA permeate flux decline $\left(F D_{O}\right)$, which relates to the beginning of the fouling of the membranes, was determined as follows:

$F D_{0}=1-\frac{J_{H A 0}}{J_{w 0}}$

where $J_{H A 0}$ corresponds to the HA permeate flux at the beginning of the filtration test.

The filtration performance of the membranes was evaluated considering the performance index $(P I)$, which takes into account the final values of both the HA permeate flux $\left(J_{H A f}\right)$ and the HA separation factor $\left(\alpha_{f}\right)$ obtained at the end of the HA test (after about $420 \mathrm{~min}$ of experiment):

$P I\left(\mathrm{~kg} / \mathrm{m}^{2} \mathrm{~h}\right)=\frac{J_{H A f} \cdot \alpha_{f}}{100}$

\section{Results and discussions}

\subsection{Characterization of the polymer solution}

The surface tension of the PSU electrospun solution is $35.8 \pm 1.8 \mathrm{mN} / \mathrm{m}$, its viscosity is $485.3 \pm 0.8 \mathrm{mPa}$ s and its electrical conductivity is $9.12 \pm 0.15 \mu \mathrm{S} / \mathrm{cm}$. Similar values for the surface tension $(35.47 \mathrm{mN} / \mathrm{m})$ and the viscosity $(520 \mathrm{mPa}$ ) of the PSU dope solution (20\% wt/v PSU in DMAC/acetone (9:1) mixed solvents) were reported by Yuan et al. [34] when preparing ultrafine PSU fibers by electrospinning.

\subsection{Preparation and characterization of PSU ENMs}

3.2.1. Preliminary evaluation of PSU ENMs prepared with different HPTs and determination of the region of interest of the HPT

A preliminary HPT study (see Fig. 1) was carried out to evaluate 90 membranes treated with 30 different HPTs in terms of damage, thickness homogeneity and degree of networking (i.e. quantity of bonding points between nanofibers) after the HPT. A visual criterion was used to evaluate the damage of the membranes due to the HPT (see Fig. S1 in SI), giving 0 points to membranes that were burned on most of the surface, 5 points to membranes with only few small burned spots or 10 points to membranes without any burned spot on the surface. The final thickness homogeneity of the membrane was evaluated by means of the relative error of the thickness $\left(E_{r}=(\Delta \delta / \delta) \cdot 100\right)$, giving $0,1.5,3.5,5$, $6.5,8.5$ or 10 points to membranes with a relative error of the thickness between $40-100,30-40,20-30,15-20,10-15,5-10$ and $0-5 \%$, respectively. Finally, SEM images of the PSU ENMs surfaces were used to evaluate the degree of networking and interconnectivity of the PSU ENMs, giving $0,2.5,5,7.5$ or 10 points to membranes with a percentage of nanofiber intersections bonded $<20,20-40,40-60,60-80$ and $>80 \%$, respectively (see Fig. S2 in SI). The individual scores from the three evaluations were averaged to obtain a normalized score from 0 to 10 for each membrane. The scores of all membranes fabricated under the same HPT condition were averaged to obtain a single score for that condition.

Fig. 1 shows a three-dimensional representation of the average

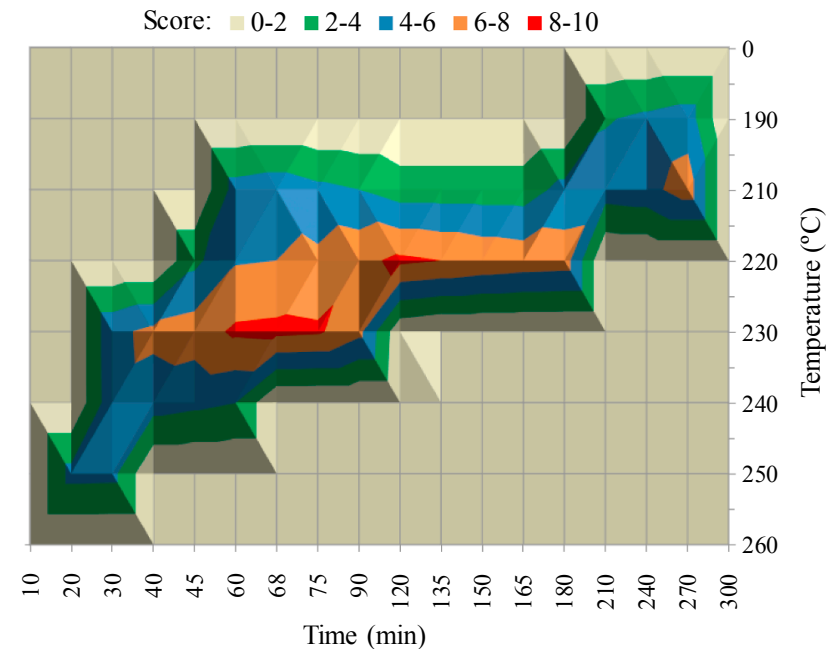

Fig. 1. 3D surface graph showing the result of the preliminary evaluation of the PSU ENMs treated with different heat post-treatments (HPTs).

scores of the different HPTs. A region of interest for further investigation was identified (average score $>6$, orange and red colors), which corresponded to $\left(210^{\circ} \mathrm{C}, \mathrm{t}>250 \mathrm{~min}\right),\left(220^{\circ} \mathrm{C}, 65<\mathrm{t}<180 \mathrm{~min}\right)$ and $\left(230^{\circ} \mathrm{C}, 35<\mathrm{t}<90 \mathrm{~min}\right)$. Eleven different HPTs within the region of interest were used to systematically study the effects of the HPT temperature and time on the morphology and structure of the PSU ENMs as well as on their filtration performance.

\subsubsection{Effects of the HPT temperature and time on the morphology and structure of PSU ENMS}

Table 1 summarizes the morphological characteristics of the eleven PSU ENMs treated with different HPTs. It must be pointed out that the HPTs used to treat the ENM $1\left(210^{\circ} \mathrm{C} / 60 \mathrm{~min}\right)$, ENM $2\left(210^{\circ} \mathrm{C} / 90 \mathrm{~min}\right)$ and ENM $3\left(220^{\circ} \mathrm{C} / 60 \mathrm{~min}\right)$ were not within the region of interest, but they were useful to systematically study the effects of the changes of the HPT temperature. Figs. 2-5 show the morphological and structural properties of the PSU ENMs prepared with the different HPTs. One of the main effects of the application of the HPT was the reduction of the thickness of the ENMs, which decreased from 900 to $80-380 \mu \mathrm{m}$, depending on the applied HPT.

The changes of the surface of the PSU ENMs when increasing the HPT temperature from 210 to $230^{\circ} \mathrm{C}$ can be observed in Fig. 2. For both 60 and $90 \mathrm{~min}$ of HPT time, an increase of the mean nanofiber diameter $\left(\lambda_{w}^{-}\right)$(see Table 1 and Fig. 4) and nanofibers interconnectivity was observed when increasing the HPT temperature, resulting in membranes with improved integrity and a more compact structure $[1,5]$. The same morphological and structural changes (i.e. increase of $\overline{\lambda_{w}}$ and the number of interconnected nanofibers) were observed by Liang. et al. [25] on PVDF ENMs when increasing the applied heat treatment temperature from 150 to $160^{\circ} \mathrm{C}$. The increase of $\lambda_{w}^{-}$is attributed to the shrinkage of the nanofibers at high temperatures $[6,23,25]$.

By comparing the SEM images of $60 \mathrm{~min}$ of HPT time with those of 90 min (Fig. 2), it can be noticed that the effect of increasing the HPT temperature was stronger at higher HPT time. For instance, ENMs 4 and 11 resulted in larger values of $\lambda_{w}^{-}$(i.e. thicker nanofibers, see Table 1 and Fig. 4) and higher degree of networking than that of the ENMs 3 and 9, respectively. Furthermore, ENMs 4 and 11 had more and larger junctions between nanofibers compared with those of the ENMs 3 and 9.

As can be seen in Fig. 3, different increments of the HPT time (30 and $15 \mathrm{~min}$ ) for the membranes treated at 220 and $230^{\circ} \mathrm{C}$, respectively, were established to avoid burning the membranes, as the effects of increasing the HPT time on the structure and morphology of the membranes were notably stronger when the applied temperature was 
Table 1

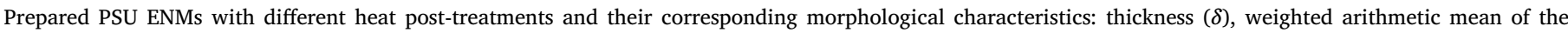

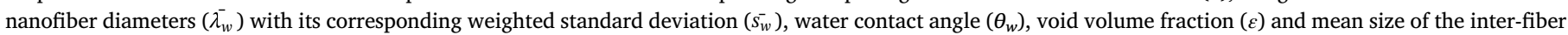
space $\left(\bar{d}_{f}\right)$.

\begin{tabular}{|c|c|c|c|c|c|c|c|}
\hline \multirow[t]{2}{*}{ Membrane } & \multicolumn{2}{|c|}{ Heat treatment } & \multicolumn{5}{|c|}{ Morphological characteristics } \\
\hline & $T\left({ }^{\circ} \mathrm{C}\right)$ & $t(\min )$ & $\delta(\mu \mathrm{m})$ & $\overline{\lambda_{w}} \pm s_{w}^{-}(\mu \mathrm{m})$ & $\theta_{w}\left({ }^{\circ}\right)$ & $\varepsilon(\%)$ & $\bar{d}_{f}(\mu \mathrm{m})$ \\
\hline ENM 1 & 210 & 60 & $338 \pm 15$ & $0.69 \pm 0.03$ & $137.4 \pm 1.7$ & $94.1 \pm 0.2$ & $3.35 \pm 0.03$ \\
\hline ENM 2 & 210 & 90 & $373 \pm 24$ & $0.70 \pm 0.06$ & $135.9 \pm 2.1$ & $92.8 \pm 0.4$ & $3.12 \pm 0.02$ \\
\hline ENM 3 & 220 & 60 & $380 \pm 69$ & $0.70 \pm 0.03$ & $135.0 \pm 3.2$ & $90.2 \pm 1.1$ & $2.98 \pm 0.03$ \\
\hline ENM 4 & 220 & 90 & $251 \pm 47$ & $0.73 \pm 0.02$ & $128.1 \pm 3.3$ & $83.6 \pm 1.7$ & $2.89 \pm 0.05$ \\
\hline ENM 5 & 220 & 120 & $116 \pm 33$ & $0.74 \pm 0.07$ & $125.2 \pm 2.8$ & $79.5 \pm 2.5$ & $2.80 \pm 0.05$ \\
\hline ENM 6 & 220 & 150 & $106 \pm 18$ & $0.77 \pm 0.04$ & $121.0 \pm 2.8$ & $77.1 \pm 2.2$ & $2.72 \pm 0.05$ \\
\hline ENM 7 & 220 & 180 & $92 \pm 18$ & $0.85 \pm 0.04$ & $120.4 \pm 2.6$ & $72.3 \pm 1.5$ & $2.65 \pm 0.05$ \\
\hline ENM 8 & 230 & 45 & $257 \pm 17$ & $0.69 \pm 0.06$ & $135.4 \pm 3.3$ & $92.3 \pm 1.2$ & $3.20 \pm 0.04$ \\
\hline ENM 9 & 230 & 60 & $213 \pm 65$ & $0.72 \pm 0.02$ & $125.7 \pm 3.1$ & $81.7 \pm 2.1$ & $3.04 \pm 0.05$ \\
\hline ENM 10 & 230 & 75 & $82 \pm 29$ & $0.76 \pm 0.03$ & $119.3 \pm 1.7$ & $80.8 \pm 1.7$ & $2.85 \pm 0.03$ \\
\hline ENM 11 & 230 & 90 & $147 \pm 17$ & $0.83 \pm 0.04$ & $115.4 \pm 3.6$ & $78.2 \pm 2.6$ & $2.67 \pm 0.03$ \\
\hline
\end{tabular}

higher. In fact, the maximum applied HPT time without observing any burned spot on the membrane was $180 \mathrm{~min}$ at $220^{\circ} \mathrm{C}$, twice as long as that for the membranes treated at $230{ }^{\circ} \mathrm{C}(90 \mathrm{~min})$.

No connection points between nanofibers could be detected on the surface of the membranes prepared with the lowest HPT times (ENM 3 , $60 \mathrm{~min}$ at $220^{\circ} \mathrm{C}$, and $\mathrm{ENM} 8,45 \mathrm{~min}$ at $230^{\circ} \mathrm{C}$ ). In these cases, the nanofibers were smaller in diameter (i.e. thinner nanofibers), cylindrical and curled. Similar nanofiber structures were also reported by Homaeigohar et al. [24] on polyethersulfone (PES) ENMs without heat-treatment.

When increasing the HPT time at 220 or $230{ }^{\circ} \mathrm{C}$, an enhancement of the degree of networking was observed and the nanofibers became thicker and flatter, resulting in membranes with a more compact structure. In addition, the inter-fiber spaces of the PSU ENMs, which
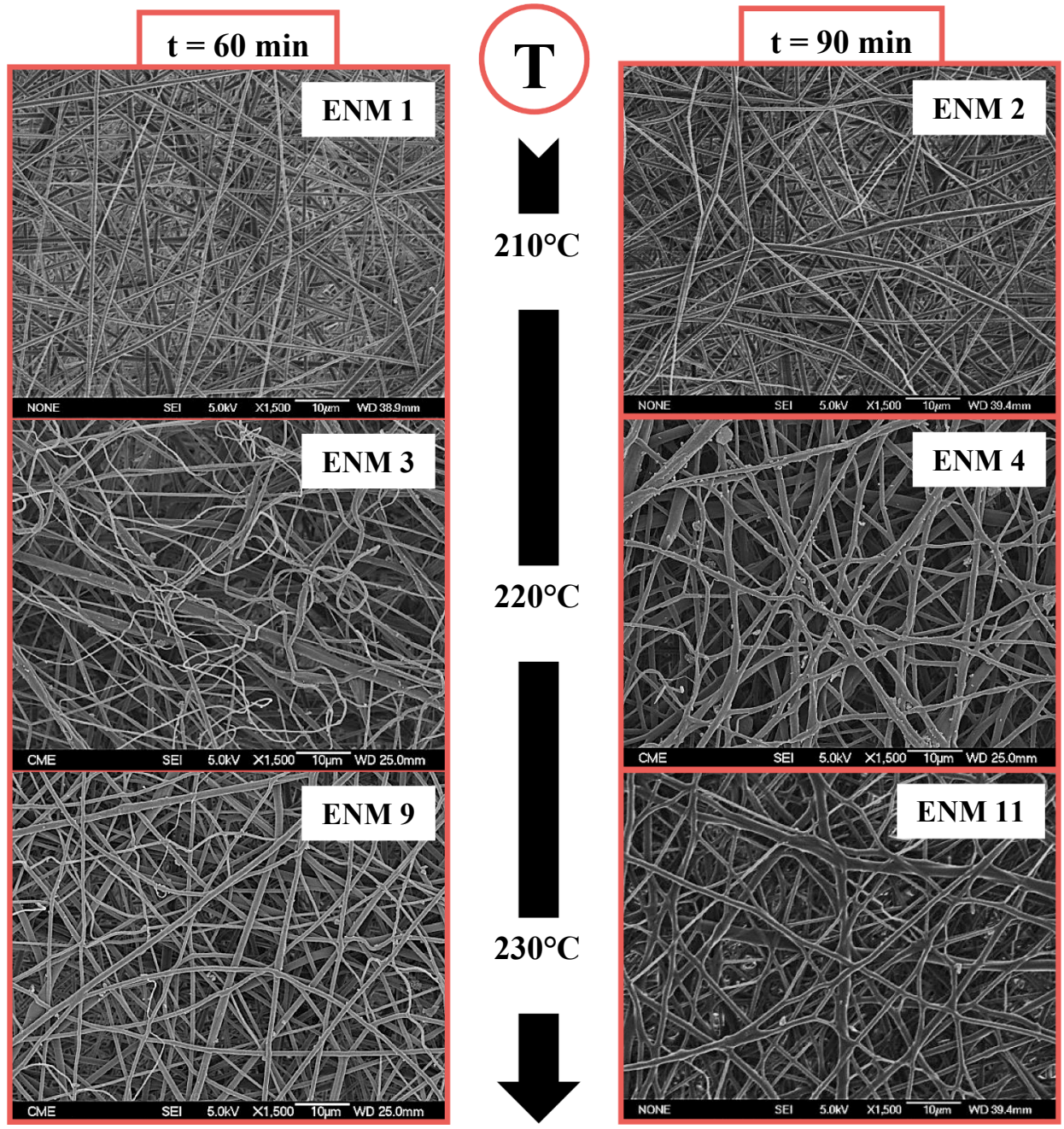

Fig. 2. SEM images of the surface of PSU ENMs prepared with a HPT time of 60 and $90 \mathrm{~min}$ at a HPT temperature of 210,220 and $230{ }^{\circ} \mathrm{C}$. All images were taken at $\times 1500$ magnification. 


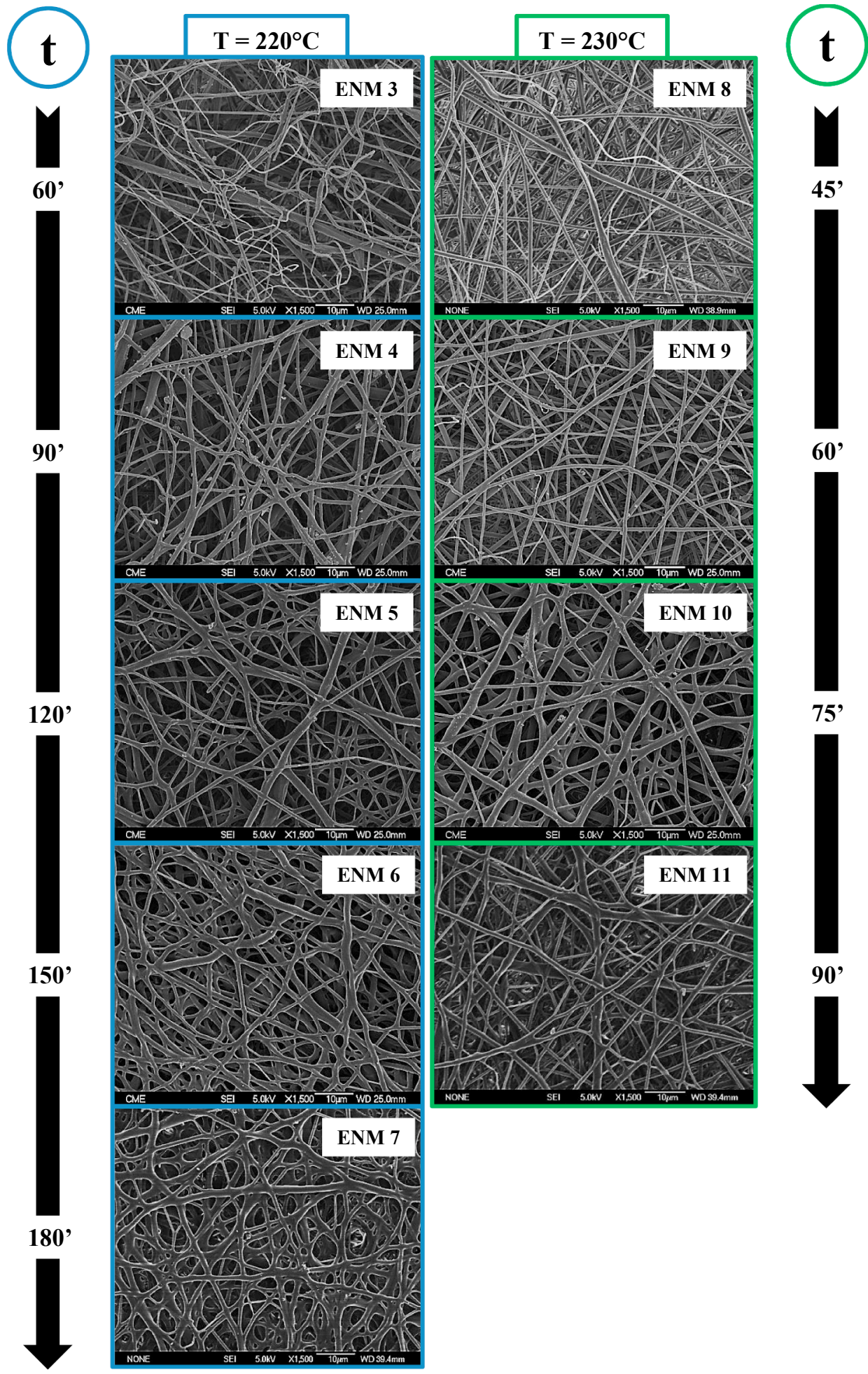

Fig. 3. SEM images of the surface of PSU ENMs prepared with a HPT temperature of 220 and $230{ }^{\circ} \mathrm{C}$ at different $\mathrm{HPT}$ times (from 45 to $180 \mathrm{~min}$ ). All SEM images were taken at $\times 1500$ magnification.

were large and without any specific geometrical shape for low HPT times, became smaller with rounder edges when the HPT time was increased. For instance, the nanofiber network of the membrane prepared with the highest HPT time, $180 \mathrm{~min}$ at $220^{\circ} \mathrm{C}$ (see SEM image of ENM 7 in Fig. 3), had relatively small and rounded inter-fiber spaces together with more fused nanofibers. Similar membrane morphologies were also observed in electrospun poly (lactic acid) (PLA) membranes treated for $120 \mathrm{~min}$ at $90{ }^{\circ} \mathrm{C}[26]$.
Increasing the HPT temperature from 210 to $230{ }^{\circ} \mathrm{C}$ led to an increase of $\lambda_{w}^{-}$by 4.6 and $18.9 \%$, respectively, for the applied HPT times of 60 and 90 min (Fig. 4A left). It is worth noting that increasing the HPT time by only $30 \mathrm{~min}$, resulted in $\sim 4$ times greater enhancement of $\lambda_{w}^{-}$at the highest HPT temperature. Higher increases of $\lambda_{w}^{-}$were achieved by increasing the HPT time from 60 to $180 \mathrm{~min}$ at $220^{\circ} \mathrm{C}$ and from 45 to $90 \mathrm{~min}$ at $230^{\circ} \mathrm{C}(22.4$ and $19.7 \%$, respectively, see Fig. $4 \mathrm{~A}$ right). Furthermore, the nanofiber diameter distribution histograms of 


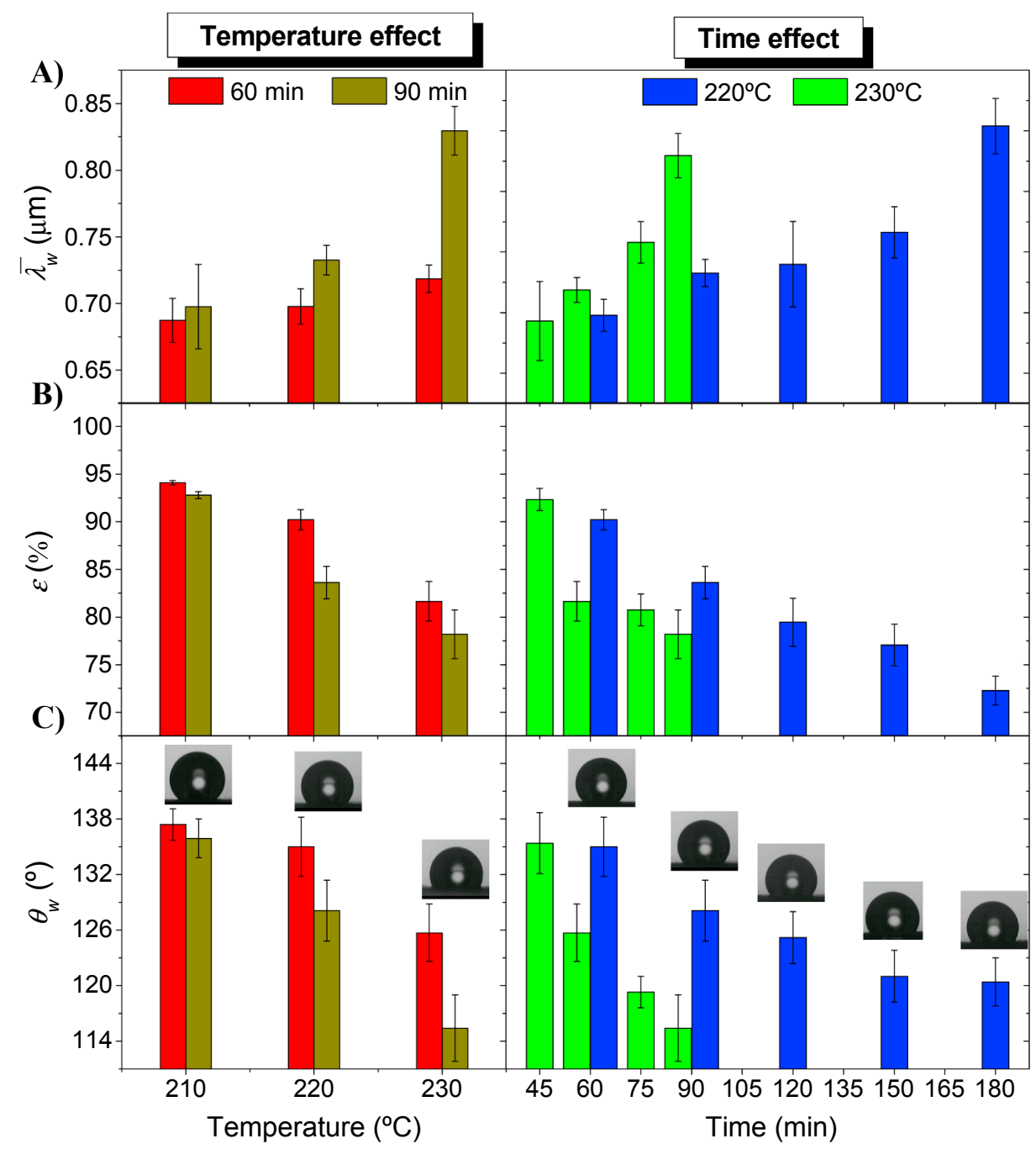

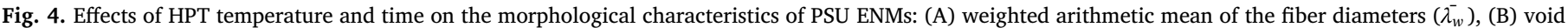
volume fraction $(\varepsilon)$ and $(C)$ water contact angle $\left(\theta_{w}\right)$. Contact angles micrographs in $(C)$ are added as supporting information of the graphics.

the PSU ENMs (Fig. S3 in SI) became broader when increasing both the HPT temperature and the HPT time as claimed by Liang et al. [25]. For example, the nanofiber diameter distribution of the ENM 7 treated at $220^{\circ} \mathrm{C}$ for $180 \mathrm{~min}(0.5$ to $1.6 \mu \mathrm{m})$ was wider than that of the ENM 3 treated at $220^{\circ} \mathrm{C}$ for $60 \mathrm{~min}(0.3$ to $1.2 \mu \mathrm{m})$.

The increse of the HPT temperature or time also resulted in a left shift of both the cumulative (CFF, Fig. 5A-B left) and the differential (DFF, Fig. 5A-B right) inter-fiber space distributions along with a decrease of the mean size of the inter-fiber space $\left(\bar{d}_{f}\right)$ of the membranes. When the HPT temperature was increased from 210 to $230{ }^{\circ} \mathrm{C}, \bar{d}_{f}$ decreased by $15.5 \%$, and when the HPT time was increased from 45 to $90 \mathrm{~min}, \bar{d}_{f}$ decreased by $18.7 \%$. The detected reduction of $\bar{d}_{f}$ was mainly caused by the increase of $\lambda_{w}^{-}$and the degree of networking (Fig. S4 in SI). The latter effect was also reported in other previous studies $[1,26]$.

The obtained values of $\lambda_{w}^{-}$(from $690 \pm 30$ to $850 \pm 40 \mathrm{~nm}$ ) and $\bar{d}_{f}$ (from 2.6 to $3.3 \mu \mathrm{m}$ ) for all PSU ENMs in this study (Table 1) are comparable to those reported by both Gopal et al. [3] for PSU ENMs treated at $188^{\circ} \mathrm{C}$ for $180 \mathrm{~min}(470 \pm 150 \mathrm{~nm} ; 2.1 \mu \mathrm{m})$ and Lui et al. [35] for PSU ENMs treated at $190^{\circ} \mathrm{C}$ for $120 \mathrm{~min}(663 \pm 254 \mathrm{~nm}$; $4.5 \mu \mathrm{m})$.

It was expected that the changes in the size of the nanofibers and the inter-fiber spaces of the PSU ENMs resulted in notable effects on the total void volume fraction and permeation properties of the membranes [36]. In fact, a gradual decrease of both the void volume fraction $(\varepsilon)$ and the water contact angle $\left(\theta_{w}\right)$ of the PSU ENMs was observed with the increase of the HPT temperature and time (Fig. 4B and C). The increase of the HPT temperature from 210 to $230^{\circ} \mathrm{C}$ caused a reduction of $\varepsilon$ by 13.2 and $15.7 \%$ when the applied HPT time was 60 and $90 \mathrm{~min}$, respectively (Fig. 4B left). Meanwhile, a reduction of $\varepsilon$ by 19.9 and $15.4 \%$ was detected when the applied HPT time was varied from 60 to $180 \mathrm{~min}$ at $220^{\circ} \mathrm{C}$ and from 45 to $90 \mathrm{~min}$ at $230^{\circ} \mathrm{C}$, respectively (Fig. 4B right). It is worth noting that although $\varepsilon$ was reduced, it still remained sufficiently high (above $70 \%$, see Table 1 ). The values of $\varepsilon$ of the prepared PSU ENMs ranged between 72.3 (ENM 7, $220^{\circ} \mathrm{C} / 180 \mathrm{~min}$ ) and $94.2 \%$ (ENM $1,210^{\circ} \mathrm{C} / 60 \mathrm{~min}$ ), which is well within the range reported for non-woven PSU ultrafine fiber mats treated at $188^{\circ} \mathrm{C}$ for $360 \mathrm{~min}$ (80-85\%) [5] and PVDF ENMs treated at $80^{\circ} \mathrm{C}$ for $30 \mathrm{~min}(85-93 \%)$ [37].

The reduction of $\theta_{w}$ of PSU ENMs (Fig. 4C) could be due to the gradual flattening of the nanofibers when increasing the HPT temperature or time, resulting in smoother membrane surfaces [38,39]. Increasing the HPT temperature from 210 to $230^{\circ} \mathrm{C}$ at a HPT time of $60 \mathrm{~min}$ decreased the values of $\theta_{w}$ from 137.4 to $125.7^{\circ}$; at a HPT time of $90 \mathrm{~min}$ it decreased the value of $\theta_{w}$ from 135.9 to $115.4^{\circ}$ (Fig. 4C left). When increasing the HPT time from 60 to $180 \mathrm{~min}$ at $220^{\circ} \mathrm{C}, \theta_{w}$ 
A)

Temperature effect
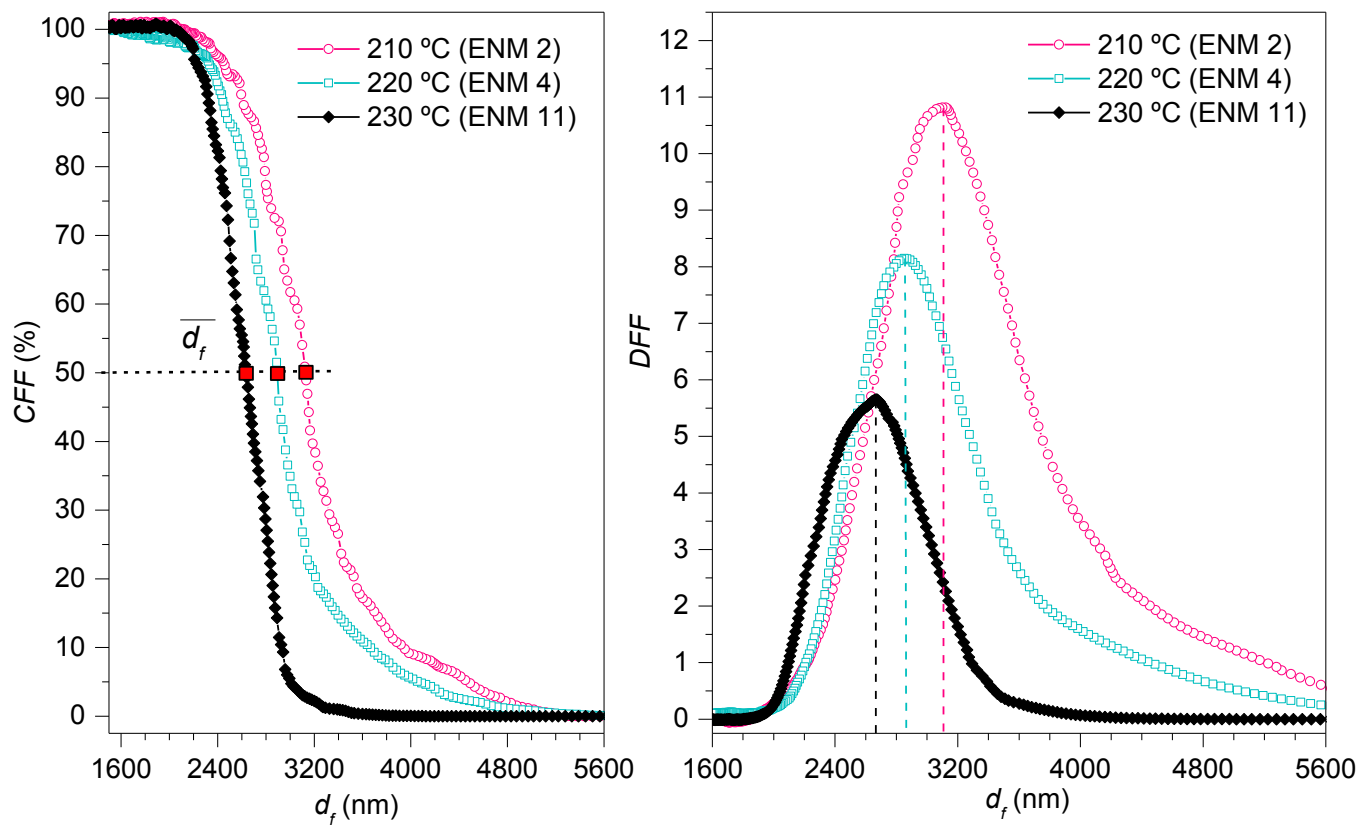

B)

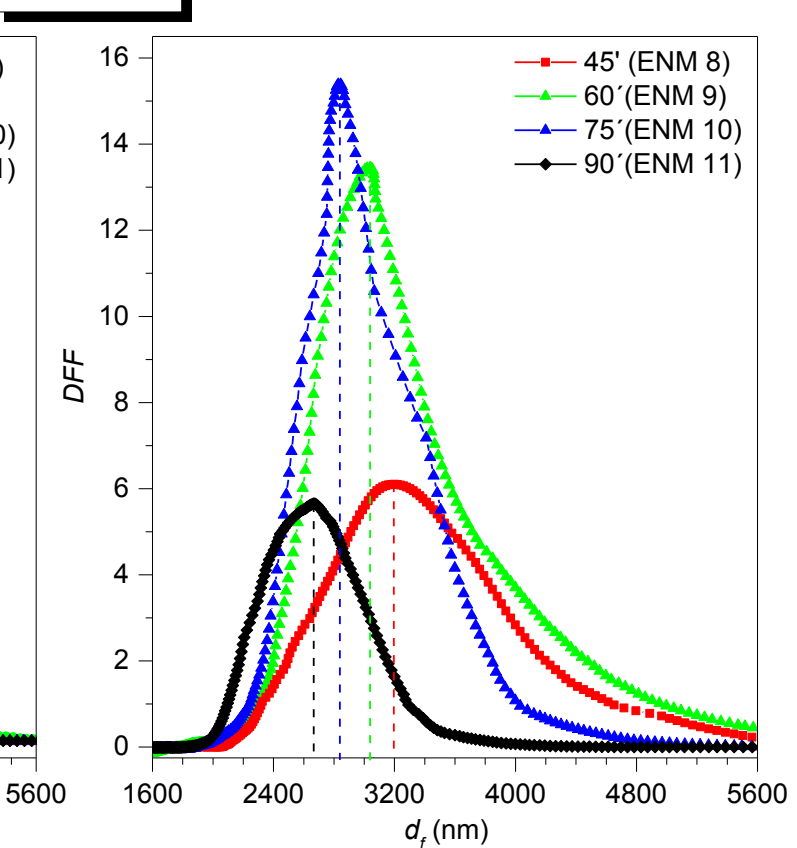

Fig. 5. Effects of HPT temperature (A) and time (B) on the mean size of the inter-fiber space $\left(\bar{d}_{f}\right)$, the inter-fiber space distribution or differential filter flow (DFF) and the cumulative filter flow distribution (CFF) of the PSU ENMs.

was reduced from 135.0 to $120.4^{\circ}$, whereas by increasing the HPT time from 45 to $90 \mathrm{~min}$ at $230{ }^{\circ} \mathrm{C}, \theta_{w}$ was reduced from 135.4 to $115.4^{\circ}$ (Fig. 4C right). During the applied HPT, the hydrophobic character of the ENMs decreased reducing the membrane water contact angles by up to $15 \%$. However, the surfaces of all heat-treated ENMs retained their hydrophobic character with contact angles $\theta_{w}>115^{\circ}$ (see Table 1). Similar $\theta_{w}$ values were reported for PSU ultrafine ENMs heat-treated at $188^{\circ} \mathrm{C}$ for $360 \mathrm{~min}\left(135 \pm 5^{\circ}\right)$ [5]. It is to be noted that the hydrophobic character was also maintained in PVDF ENMs heat-treated at $120^{\circ} \mathrm{C}$ for $120 \mathrm{~min}\left(127.0 \pm 1.1^{\circ}\right)$ [40] and PVDF-HFP ENMs hotpressed at $200^{\circ} \mathrm{C}$ for $2 \mathrm{~s}\left(125.0 \pm 2.5^{\circ}\right)$ [21].

All observed trends of the morphological characteristics $\left(\uparrow \lambda_{w}^{-}, \downarrow \bar{d}_{f}, \downarrow\right.$ $\left.\varepsilon, \downarrow \theta_{w}\right)$ of the PSU ENMs when increasing the HPT temperature or time, correlated well with the changes of the surface and the morphology of the PSU ENMs (higher interconnectivity and more compact structure), which were larger for the ENMs 7 and 11.

The SEM images and the morphological characteristics of the membranes treated at a HPT temperature of $220^{\circ} \mathrm{C}$ and the membranes treated at $230^{\circ} \mathrm{C}$ but for half the HPT time were similar. For instance, the differences of $\lambda_{w}^{-}, \bar{d}_{f}, \varepsilon$ and $\theta_{w}$ between the ENMs 5 and $9\left(220^{\circ} \mathrm{C} /\right.$ $120 \mathrm{~min}$ and $230^{\circ} \mathrm{C} / 60 \mathrm{~min}$ ) were smaller than $2.7 \%$ while for the ENMs 6 and $10\left(220^{\circ} \mathrm{C} / 180 \mathrm{~min}\right.$ and $\left.230^{\circ} \mathrm{C} / 90 \mathrm{~min}\right)$ the differences were smaller than $4.8 \%$. Therefore, similar filtration properties (i.e. separation factor and permeation fluxes) of these membranes are 
Table 2

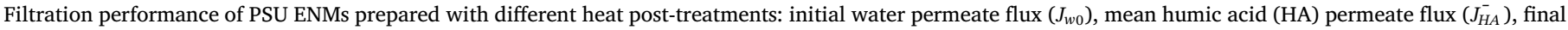
HA permeate flux $\left(J_{H A f}\right)$, final HA separation factor $\left(\alpha_{f}\right)$, irreversible fouling factor $\left(F R_{w}\right)$ and performance index $(P I)$.

\begin{tabular}{|c|c|c|c|c|c|c|c|c|}
\hline \multirow[t]{2}{*}{ Membrane } & \multicolumn{2}{|c|}{ Heat treatment } & \multicolumn{6}{|c|}{ Filtration characteristics } \\
\hline & $T\left({ }^{\circ} \mathrm{C}\right)$ & $t(\min )$ & $J_{w 0}\left(10^{2} \frac{\mathrm{kg}}{\mathrm{m}^{2} \mathrm{~h}}\right)$ & $J_{H A}^{-}\left(10^{2} \frac{\mathrm{kg}}{\mathrm{m}^{2} \mathrm{~h}}\right)$ & $J_{H A f}\left(\frac{\mathrm{kg}}{\mathrm{m}^{2} \mathrm{~h}}\right)$ & $\alpha_{f}(\%)$ & $F R_{w}(\%)$ & $P I\left(\frac{\mathrm{kg}}{\mathrm{m}^{2} \mathrm{~h}}\right)$ \\
\hline ENM 1 & 210 & 60 & $196 \pm 21$ & $116 \pm 12$ & $8590 \pm 919$ & $0.8 \pm 1.0$ & $81.9 \pm 2.8$ & $65 \pm 22$ \\
\hline ENM 2 & 210 & 90 & $199 \pm 22$ & $84.1 \pm 9.0$ & $1899 \pm 203$ & $3.7 \pm 1.2$ & $93.1 \pm 1.1$ & $70 \pm 14$ \\
\hline ENM 3 & 220 & 60 & $205 \pm 22$ & $66.6 \pm 7.1$ & $1923 \pm 206$ & $0.8 \pm 1.1$ & $91.7 \pm 1.3$ & $16 \pm 10$ \\
\hline ENM 4 & 220 & 90 & $204 \pm 22$ & $27.7 \pm 3.0$ & $337 \pm 36$ & $33.1 \pm 2.0$ & $96.4 \pm 0.5$ & $111 \pm 14$ \\
\hline ENM 5 & 220 & 120 & $194 \pm 19$ & $10.0 \pm 0.7$ & $222 \pm 18$ & $57.2 \pm 0.6$ & $98.3 \pm 0.3$ & $127 \pm 10$ \\
\hline ENM 6 & 220 & 150 & $182 \pm 19$ & $4.5 \pm 0.5$ & $170 \pm 18$ & $65.3 \pm 0.5$ & $96.8 \pm 0.5$ & $111 \pm 12$ \\
\hline ENM 7 & 220 & 180 & $153 \pm 17$ & $3.2 \pm 0.3$ & $104 \pm 11$ & $65.5 \pm 0.4$ & $98.9 \pm 0.2$ & $68 \pm 7$ \\
\hline ENM 8 & 230 & 45 & $184 \pm 20$ & $34.8 \pm 3.7$ & $306 \pm 33$ & $37.0 \pm 0.6$ & $97.7 \pm 0.4$ & $113 \pm 12$ \\
\hline ENM 9 & 230 & 60 & $206 \pm 22$ & $20.0 \pm 2.1$ & $232 \pm 26$ & $63.6 \pm 0.7$ & $95.9 \pm 0.6$ & $147 \pm 17$ \\
\hline ENM 10 & 230 & 75 & $203 \pm 22$ & $9.9 \pm 1.1$ & $188 \pm 20$ & $70.9 \pm 0.4$ & $96.8 \pm 0.5$ & $133 \pm 14$ \\
\hline ENM 11 & 230 & 90 & $156 \pm 17$ & $3.6 \pm 0.4$ & $99 \pm 11$ & $75.0 \pm 0.3$ & $99.0 \pm 0.1$ & $74 \pm 8$ \\
\hline
\end{tabular}

expected.

\section{3. $M F$ tests}

As mentioned above, electrospun nanofibers exhibit, due to their nanostructure, very large water contact angles compared to polymeric films made from the same material (i.e. phase inversion flat membrane prepared with the same polymer). In this study, PSU ENMs exhibited contact angles between 115 and $137^{\circ}$. However, phase-inversion PSU membranes are reported to exhibit contact angle values around $70-80^{\circ}$ [7]. Therefore, there is an initial 'resistance' for water to enter a completely dry ENM. Once the ENM is wetted, the high void volume fraction of the ENM leads to relatively high flow rates. ENMs are prone to be compressed during filtration because of their high void volume fraction and their relatively poor nanofiber adhesion. Therefore, to open and wet all the inter-fiber spaces of the PSU ENMs and to ensure that the water permeate flux kept constant with filtration time at an applied pressure, a water compaction step was carried out before the MF tests. Subsequently, HA MF tests were conducted with a $15 \mathrm{mg} / \mathrm{L}$ HA solution at $\mathrm{pH} 11$ for all the PSU ENMs. The filtration results of all the PSU ENMs are summarized in Table 2.

\subsubsection{Effects of the HPT temperature and time on the filtration performance of PSU ENMS}

The effects of the HPT temperature and time on the filtration performance of the PSU ENMs were evaluated analysing the changes of the HA permeate fluxes $\left(J_{H A}\right)$, the HA separation factor $(\alpha)$ and the irreversible fouling factors $\left(F R_{W}\right)$ (Fig. $6 \mathrm{~A}$ and $\mathrm{B}$, shown as an example) with the filtration time, and by comparing their performance indexes (PI) (Fig. 8).

Fig. 6A shows the effects of increasing the HPT temperature (at a fixed HPT time of $90 \mathrm{~min}$ ) from 210 to $230^{\circ} \mathrm{C}$ (PSU EMNs 2, 4, and 11). A considerable decrease of $J_{H A}$ along with a gradual increase of $\alpha$ and $F R_{W}$ was observed. The final HA permeate flux $\left(J_{H A f}\right)$ of the PSU ENMs decreased by $82.2 \%$ when increasing the HPT temperature from 210 to $220^{\circ} \mathrm{C}$ (ENM 2 to ENM 4) and by $70.6 \%$, when increasing the HPT temperature from 220 to $230{ }^{\circ} \mathrm{C}$ (ENM 4 to ENM 11). The final HA separation factor $\left(\alpha_{f}\right)$ of ENM $4\left(220^{\circ} \mathrm{C}\right)$ was $88.9 \%$ larger than that of ENM $2\left(220^{\circ} \mathrm{C}\right)$ and that of ENM $11\left(230^{\circ} \mathrm{C}\right)$ was $55.9 \%$ larger than that of ENM 4. However, the respective changes of $F R_{W}(3.6$ and 2.7\%) were not as noticeable as those of $J_{H A}$ and $\alpha$.

The initial permeate flux decline $\left(F D_{0}\right)$ was $0.15,0.19$ and 0.92 for ENM 2, ENM 4 and ENM 11, respectively. This means that the permeate flux of the membrane prepared with the lowest HPT temperature $\left(210^{\circ} \mathrm{C}\right.$, ENM 2) was reduced only by $15 \%$ during the first minutes of HA filtration whereas that of the membrane prepared with a higher HPT temperature $\left(230^{\circ} \mathrm{C}\right.$, ENM 11$)$ was declined by $92 \%$.
These differences in the filtration performance of the membranes are mainly related to their different structural morphology. For instance, the membrane prepared with low HPT temperature $\left(210^{\circ} \mathrm{C}\right.$, ENM 2) exhibited the largest $\bar{d}_{f}(3.1 \mu \mathrm{m})$ and $\varepsilon(92.8 \%)$ and, therefore had the highest mean HA permeate flux (i.e. average of all the HA permeate fluxes during the MF test; $J_{H A}^{-}=8406 \mathrm{~kg} / \mathrm{m}^{2} \mathrm{~h}$ ) with the lowest $\alpha_{f}$ value (3.7\%). On the other hand, the membrane treated with the highest temperature $\left(230{ }^{\circ} \mathrm{C}\right.$, ENM 11$)$ had the smallest $\bar{d}_{f}(2.6 \mu \mathrm{m})$ and $\varepsilon(78.2 \%)$ values and exhibited the lowest $J_{H A}^{-} \quad\left(358 \mathrm{~kg} / \mathrm{m}^{2} \mathrm{~h}\right)$ with the highest $\alpha_{f}$ (75\%) values. It is worth nothing that although the ENM 11 had a $J_{H A}^{-}$value of $92.3 \%$ lower than that of ENM 2, its PI value resulted to be higher $\left(74 \mathrm{~kg} / \mathrm{m}^{2} \mathrm{~h}\right)$ than that of the ENM $2\left(70 \mathrm{~kg} / \mathrm{m}^{2} \mathrm{~h}\right)$ because of its larger separation factor. Similar results were reported by Li et al. [26] with poly (lactic acid) (PLA) ENMs when increasing the HPT temperature from 90 to $95^{\circ} \mathrm{C}$ (at a fixed HPT time of $30 \mathrm{~min}$ ). A decrease in the inter-fiber space of these membranes (from 2.3 to $2.0 \mu \mathrm{m}$ ) resulted in a permeate flux decline (from about 26,000 to $8500 \mathrm{~L} / \mathrm{m}^{2} \mathrm{~h}$ ) along with an increase of the separation factor of $\mathrm{TiO}_{2}$ particles (from 61 to $85 \%$ ).

Fig. 6B shows the effects of the HPT time (at a fixed HPT temperature of $230^{\circ} \mathrm{C}$ ) on the filtration performance of the PSU EMNs 8 (45 $\mathrm{min}), 9(60 \mathrm{~min}), 10(75 \mathrm{~min})$ and $11(90 \mathrm{~min})$. In this case, the effects on $J_{H A}$ and $\alpha$ when increasing the HPT time from 45 to $90 \mathrm{~min}$ were not as noticeable as those observed when the HPT temperature was increased from 210 to $230{ }^{\circ} \mathrm{C}$. For instance, a gradual reduction of $J_{H A f}(20.9,22.3$ and $47.3 \%)$ and an increase of $\alpha_{f}(41.8,10.3$ and $5.6 \%)$ were observed when increasing the HPT time from 45 to 60 , from 60 to 75 and from 75 to $90 \mathrm{~min}$, respectively. The $F R_{W}$ values did not follow a clear trend. The membrane with the lowest value of $F R_{W}(95.9 \%)$ was the one treated for $60 \mathrm{~min}$ (ENM 6).

The values of $F D_{0}$ for the ENMs 8, 9, 10 and 11 were $0.40,0.55,0.79$ and 0.92 , respectively, indicating that the initial permeate flux decline increased progressively when increasing the HPT time. It can also be noticed in Fig. 6B that all membranes reached a relatively constant $J_{H A}$ value after $360 \mathrm{~min}$ of filtration time. As mentioned before, the changes in filtration performance of the PSU ENMs are directly related to their morphological and structural changes. The longer the HPT treatment time, the more compact was the membrane structure and the thicker and more interconnected were their nanofibers (i.e. higher $\lambda_{w}^{-}$and smaller $\bar{d}_{f}$; see Table 1, Fig. 3 , and Fig. $5 \mathrm{~B}$ ). These resulted in a reduction of $J_{H A}^{-}$from $3481 \mathrm{~kg} / \mathrm{m}^{2} \mathrm{~h}$ for ENM 8 ( $45 \mathrm{~min}$ ) to $358 \mathrm{~kg} / \mathrm{m}^{2} \mathrm{~h}$ for ENM 11 (90 min) and an enhancement of $\alpha_{f}$ from 37.0 to $75.0 \%$, respectively (see Table 2 ). The membranes prepared at $230{ }^{\circ} \mathrm{C}$ with the lowest HPT time (ENM $8,113 \mathrm{~kg} / \mathrm{m}^{2} \mathrm{~h}$ ) and the highest HPT time (ENM $11,74 \mathrm{~kg} / \mathrm{m}^{2} \mathrm{~h}$ ) both had smaller PI values than those treated for intermediate HPT times (ENM 9, $147 \mathrm{~kg} / \mathrm{m}^{2} \mathrm{~h}$, and ENM 10, $133 \mathrm{~kg}$ / $\left.\mathrm{m}^{2} \mathrm{~h}\right)$. 
A)

Temperature effect
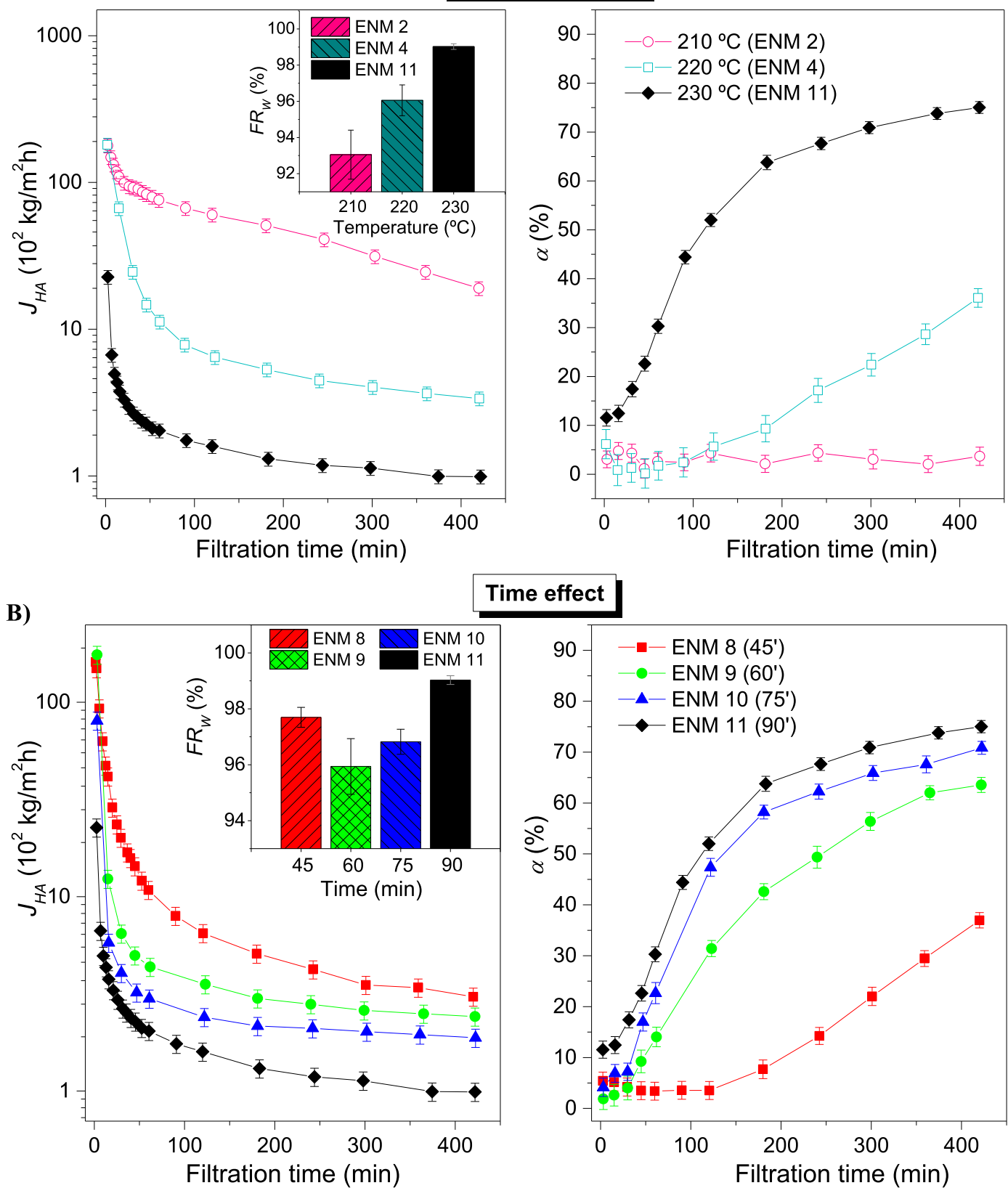

Time effect

B)

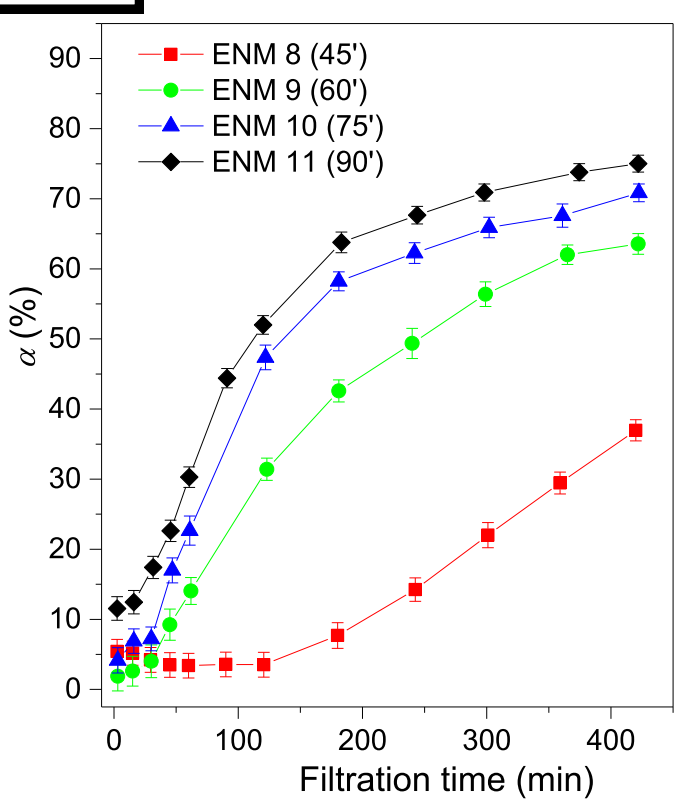

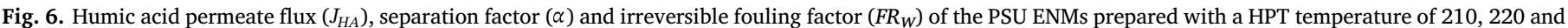

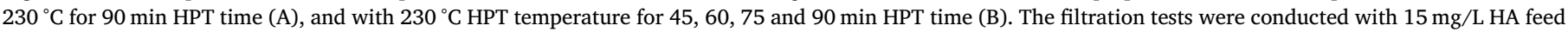
aqueous solution at $\mathrm{pH} 11$ and $10^{5} \mathrm{~Pa}$ transmembrane pressure $(\Delta P)$.

As mentioned in the introduction, fouling is a major factor limiting the application of membranes in water treatment. Thus, a characterization analysis of the organic fouling generated on the membranes after MF tests was conducted. FTIR, SEM imaging and EDS mapping were used to confirm the presence of HA across the PSU ENMs, to compare the surface morphology of the membranes before and after filtration and to measure the change of the atomic composition of the membranes due to the organic fouling (Fig. S5).

The $J_{H A}$ and $\alpha$ curves plotted in Fig. 6 can be used to study the fouling phenomenon of the PSU ENMs. HA fouling in MF membranes has two stages: i) a pore blockage that corresponds to a rapid HA permeate flux decline due to the deposition of large HA aggregates on the surface and in the pores (inter-fiber space for ENMs) of the membrane; ii) a cake filtration that induces a slow decrease of the HA permeate flux with filtration time until a relatively constant value of the permeate flux (known as steady-state value or asymptotic permeate flux) is reached. During this second stage a HA deposit or cake layer forms on those regions of the membrane that were covered by HA aggregates during the first stage [14,41-44].

The transition between the pore blockage and the cake filtration stage is usually determined by the change of the slopes of both the permeate flux and separation factor curves with filtration time. The time $\left(t_{c}\right)$ at which this change occurs is known as the "critical point". A smaller $t_{c}$ indicates a shorter length of the initial pore blocking stage, and hence a faster fouling evolution rate. The value of $t_{c}$ depends mainly on the morphological and structural characteristics of each PSU ENM (e.g. mean size of the inter-fiber space, inter-fiber space distribution, void volume fraction, mean nanofiber diameter, 
hydrophobicity, etc.).

From Fig. $6 \mathrm{~B}$ it can be seen that the pore blockage of the PSU ENMs prepared with higher HPTs (i.e. ENMs 9, 10 and 11) occurred faster, during the first half an hour of filtration $\left(t_{c}<30 \mathrm{~min}\right)$. This is attributed to their more compact structure and smaller size of the inter-fiber space, which promotes the pore blockage phenomenon $[45,46]$. For these membranes, the slope of the $\alpha$ curve was relatively small until the critical time $t_{c}$ (i.e. beginning of pore blockage stage) was reached. Subsequently, a considerable increase of $\alpha$ was observed (due to the reduction of the membrane inter-fiber space during the pore blockage stage and during the formation and growth of the cake layer in the second stage), followed by a slower increase of $\alpha$ (attributed to the reached cake layer mature stage). A relatively steady-state value of the HA separation factor $\left(\alpha_{f}\right)$ was obtained at the end of the filtration test (70.9, 75.0 and 77.6\% for the ENMs 9, 10 and 11, respectively).

For the membranes prepared with low HPTs (i.e. ENMs 4 and 8, see Fig. $6 \mathrm{~A}$ and $\mathrm{B}$ ), the slope of the $\alpha$ curve was relatively constant and close to zero during the first $125 \mathrm{~min}$ of filtration (i.e. pore blockage stage with $t_{c} \approx 125 \mathrm{~min}$ ). Then it increased considerably during the next 300 min of filtration time (i.e. cake filtration), reaching values up to $37 \%$. The membrane prepared with the lowest HPT (i.e. ENM 2) did not retain HA, most likely due to the low quantity of bonding points between nanofibers (see SEM image in Fig. 2). Unbounded nanofibers may be displaced by the hydrostatic water pressure leading to a broad inter-fiber space of the ENM and allowing HA particles to penetrate through the membrane resulting in no separation. The $\alpha_{f}$ values of all the PSU ENMs ranged from 1 to $78 \%$ (see Table 2). This elucidates the clear differences of the morphological characteristics of the PSU ENMs and confirms the important influence of the HPT on the filtration performance of the membranes.

In the previous section it was reported that the morphological and structural characteristics of the membranes treated at a HPT temperature of $220^{\circ} \mathrm{C}$ during a time $t$ and those treated at $230{ }^{\circ} \mathrm{C}$ during a time $\mathrm{t} / 2$ were very similar. For this reason, a comparison of the filtration properties (i.e. $J_{H A}, \alpha$ and $F R_{W}$ ) of the membrane pairs ENMs 4-8, 5-9, 6-10 and 7-11 was performed (Fig. 7). Their $J_{H A f}$ values were approximately the same (see Table 2 ) with deviations below $10.2 \%$. Similarly, the same tendency was observed for the curves of $\alpha$ as a function of filtration time for each pair of membranes. In particular, the $\alpha$ curves of the membranes prepared with lower HPTs (i.e. ENMs 4 and 8) overlapped, while only small differences were detected for the pairs of membranes prepared with higher HPTs (i.e. ENMs 5-9, 6-10 and $7-11)$. Taking into account their mean $\alpha$ for the entire filtration process

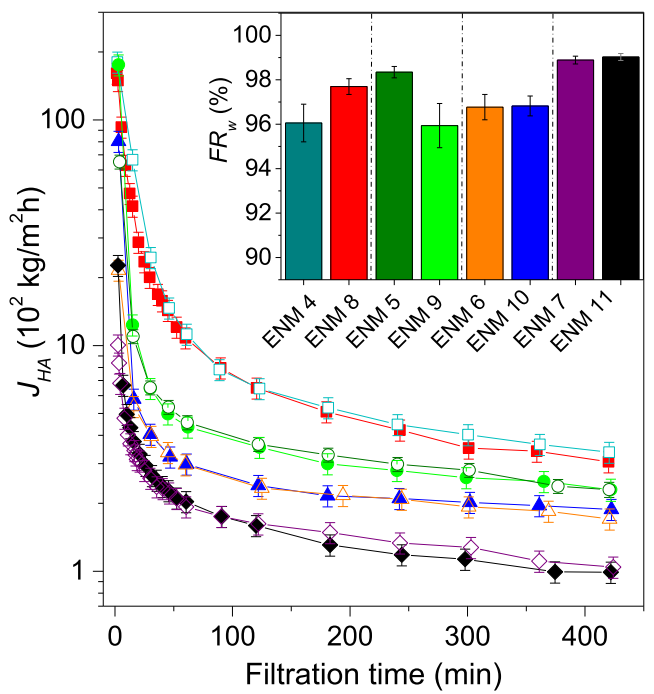

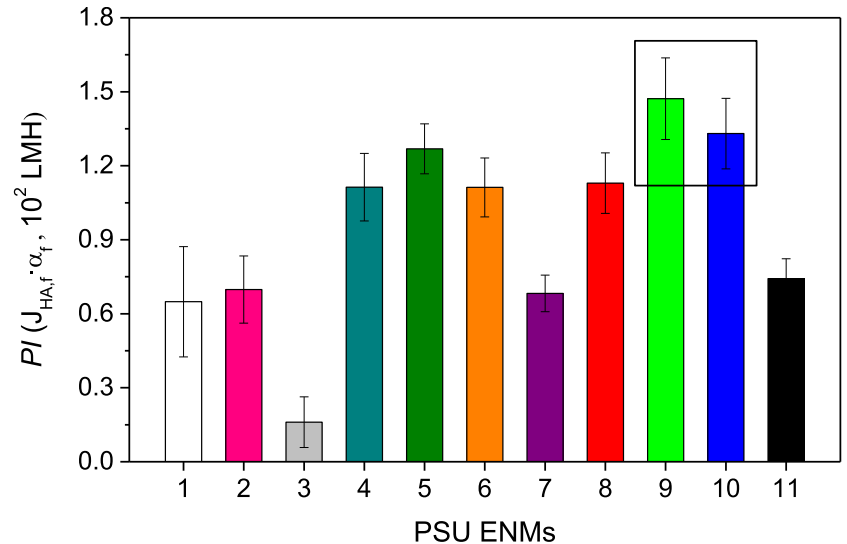

Fig. 8. Performance index $(P I)$ of the PSU ENMs prepared with different HPT conditions.

$(\bar{\alpha})$, the deviation between these values was low and ranged between 4.1 and $11.9 \%$, the maximum deviation corresponding to the membranes prepared with the highest HPTs (i.e. EMN $7(\bar{\alpha}=39.6 \%)$ and ENM $11(\bar{\alpha}=45.0 \%)$. It is worth noting that despite the similarities in the filtration behaviour of the pairs of membranes, higher $\alpha_{f}$ values were obtained for all the membranes treated at $230^{\circ} \mathrm{C}$ compared to those treated at $220^{\circ} \mathrm{C}$ for a double HPT time. By comparing the values of $F R_{W}$ of the different pairs of membranes (Table 2 and Fig. 7) no clear conclusion could be drawn. The deviation of the $F R_{W}$ values of the pairs of membranes prepared with higher HPTs (i.e. ENMs 6-10 and 7-11) was smaller than $0.2 \%$, while the highest deviation (2.5\%) was reached for the pair of ENMs 5-9.

Despite the similarities in the filtration characteristics between the pairs of membranes, PSU ENMs treated at $230^{\circ} \mathrm{C}$ had up to $16.4 \%$ greater PI values than PSU ENMs treated at $220^{\circ} \mathrm{C}$. Therefore, it is advisable to increase the HPT temperature by $10^{\circ} \mathrm{C}$ and reduce the HPT time by half as it permits energy and cost savings.

\subsubsection{Comparative study}

The pure water permeability ( $P W P$ ) of all prepared PSU ENMs measured after compaction ranged from 15,260 to $20,563 \mathrm{~kg} / \mathrm{m}^{2} \mathrm{~h}$ bar, which is 3 -fold to 100 -fold higher than those achieved by highly porous lab-made PSU ENMs $\left(1472-5648 \mathrm{~kg} / \mathrm{m}^{2} \mathrm{~h}\right.$ bar) [3] and PVDF ENMs $\left(232-1984 \mathrm{~kg} / \mathrm{m}^{2} \mathrm{~h}\right.$ bar) [2] used for particulate removal, and similar or greater than those reported for mechanically enhanced lab-made PES

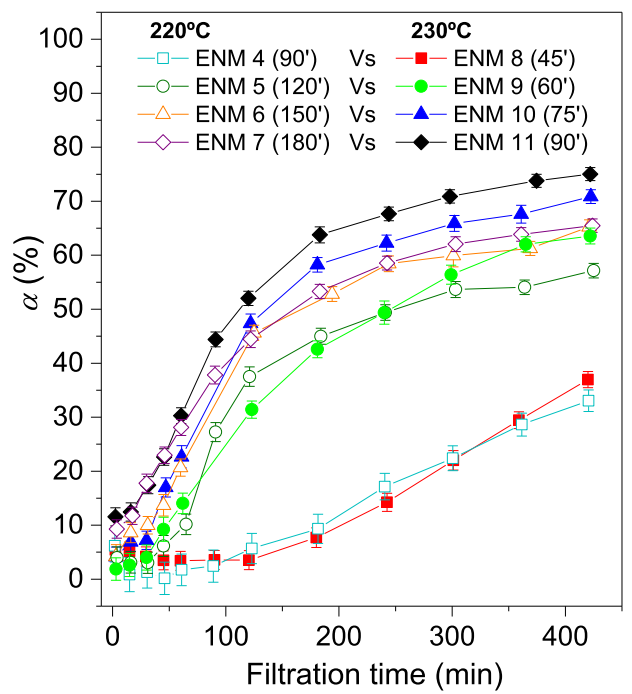

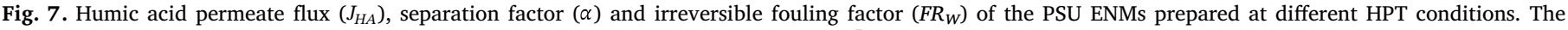
filtration tests were conducted with $15 \mathrm{mg} / \mathrm{L}$ HA feed aqueous solution at $\mathrm{pH} 11$ and $10^{5} \mathrm{~Pa}$ transmembrane pressure $(\Delta P)$. 


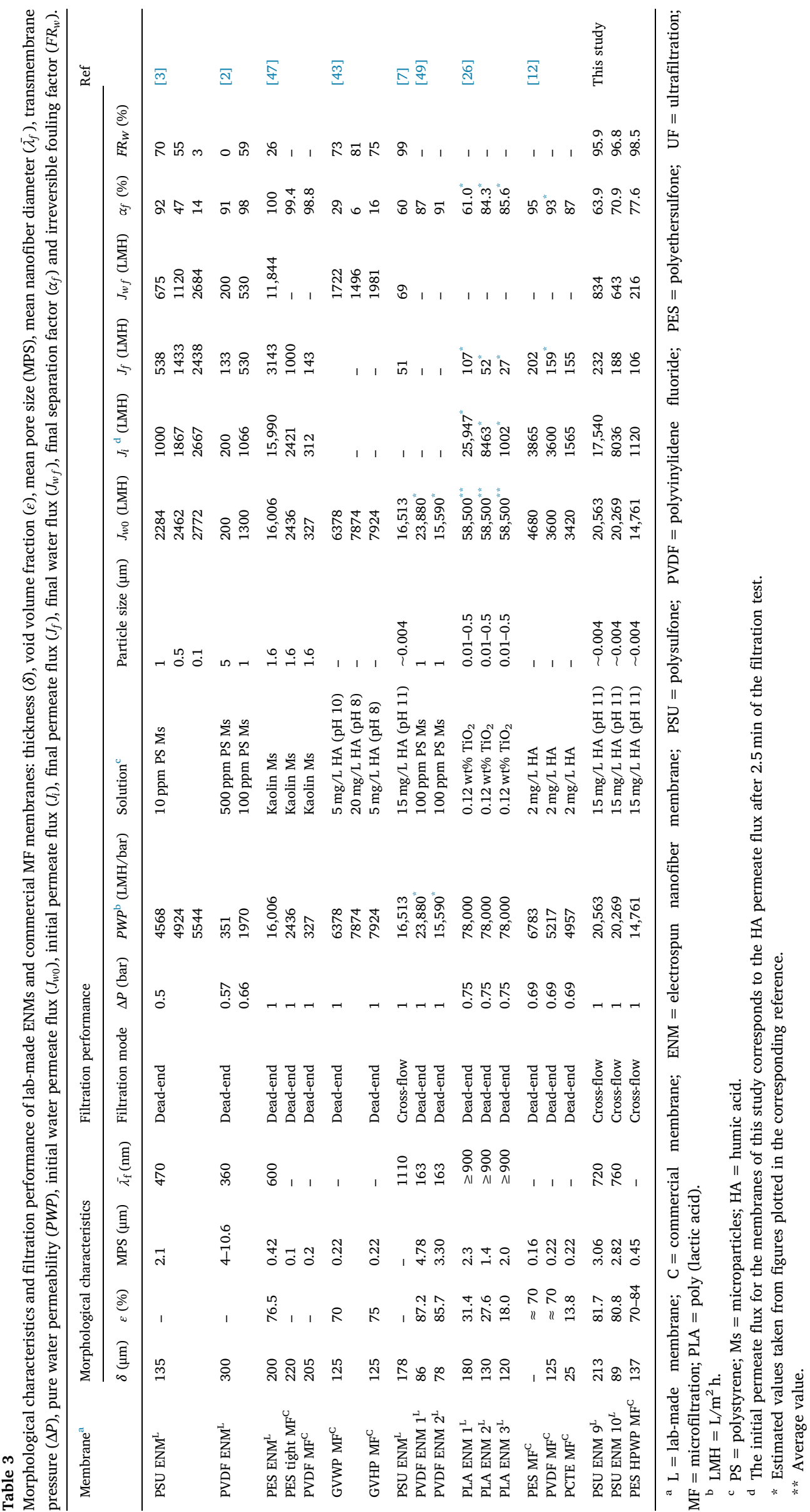


ENMs $\left(16,006 \mathrm{~kg} / \mathrm{m}^{2} \mathrm{~h}\right.$ bar) [47]. In addition, the $P W P$ values obtained in the present study for PSU ENMs were larger than those of commercial flat sheet membranes typically used in MF processes (i.e. PVDF MF: $2436 \mathrm{~kg} / \mathrm{m}^{2} \mathrm{~h}$ bar, Model V0.2, Synder Membrane Technology [47]; PES tight MF: $327 \mathrm{~kg} / \mathrm{m}^{2} \mathrm{~h}$ bar, Model LX, Synder Membrane Technology [47]; GVHP MF: $8875 \mathrm{~kg} / \mathrm{m}^{2} \mathrm{~h}$ bar, Millipore [43]; PES OMEGA MF: $6783 \mathrm{~kg} / \mathrm{m}^{2} \mathrm{~h}$ bar, Filtron Technology [12]; PVDF DURAPORE MF: $5217 \mathrm{~kg} / \mathrm{m}^{2} \mathrm{~h}$ bar, Millipore [12]; PES HPWP MF: $14,761 \mathrm{~kg} / \mathrm{m}^{2} \mathrm{~h}$ bar, Millipore; see Table 3). These values confirm the structural advantages of the ENMs over traditional water filtration membranes, such as their three-dimensional-inter-pore connectivity and high void volume fractions (i.e. higher porosity leads to more channels for water flow) $[46,48]$. In addition, the treated PSU ENMs had a small water entry pressure (below 1 bar), which is convenient for low-pressure water purification and therefore for MF applications. (Table 3: Ref. $[2,3,7,12,26,43,47,49])$.

In this study, the final permeate fluxes $\left(J_{f}\right)$ measured after $7 \mathrm{~h}$ of filtration for the PSU ENMs with the highest PI values (i.e. ENMs 9 and 10) are 188 and $232 \mathrm{~kg} / \mathrm{m}^{2} \mathrm{~h}$ (Table 3). These values are 3.7 to 4.5 times greater than the obtained one in our previous study $(51.3 \mathrm{~kg} /$ $\mathrm{m}^{2} \mathrm{~h}$ ) [7]. In addition, the values of $\alpha_{f}$ of ENMs 9 and 10 are 6.5 and $18.2 \%$ greater than the highest value obtained in our former work (60\%) [7]. Thus, the optimized HPT improved the filtration PI of the membranes up to 5-fold [7].

The final normalized permeate fluxes $\left(J_{f}\right)$ by the applied pressure $(\Delta P)$ of the ENMs 9 and 10 (232 and $188 \mathrm{~kg} / \mathrm{m}^{2} \mathrm{~h}$ bar) are 63 and $32 \%$ greater than that of the eco-efficient, micro-porous, lab-made PLA ENM $1\left(143 \mathrm{~kg} / \mathrm{m}^{2} \mathrm{~h}\right.$ bar) [26]. The values of $\alpha_{f}$ measured for ENMs 9 and 10 are also 5 and $16 \%$ higher than that of the PLA ENM 1. The values of PI of ENMs 9 and 10 are therefore 53 and 69\% greater than that of PLA ENM 1, which confirms the high filtration performance of the heattreated optimized ENMs.

The commercial MF membranes (PES MF, PVDF MF and PCTE MF) used by Yuan and Zydney [12] for the treatment of $2 \mathrm{mg} / \mathrm{L}$ HA solutions had up to $33 \%$ smaller $J_{f}$ values than those of the PSU ENMs 9 and 10, which were used to treat higher concentrated HA solutions $(15 \mathrm{mg} / \mathrm{L})$. This is probably due to their lower porosity and smaller mean pore size. However, the commercial MF membranes exhibited higher $\alpha_{f}$ values (up to 49\%) when compared with the PSU ENMs 9 and 10, mainly caused by their smaller mean pore size. Considering that the average size of HA particles in a basic environment ranges from 0.3 to $4 \mathrm{~nm}$ [7] and the mean size of the inter-fiber space of the PSU ENMs ranges from 2 to $4 \mu \mathrm{m}$, the values of $\alpha_{f}$ obtained for the ENMs 9 and 10 (63.9 and $70.9 \%$, respectively) can be considered reasonably good. The measured values of $\alpha_{f}$ are probably affected by both the high tortuosity of the ENMs (i.e. HA molecules are expected to be more prone to mechanical entrapment in the thread-like network of an ENM [46]) and the rejection mechanism in a fibrous structured membrane, which includes sieving, electrostatic attraction, diffusion and inertia [47].

For sake of comparison, a commercial PES MF membrane (HPWP, hydrophilic, Millipore) was tested in this study following exactly the same filtration procedure than that of the PSU ENMs. The results are summarized in Table 3. The PES MF commercial membrane has lower $J_{f}$ value (up to 55\%) but a higher $\alpha_{f}$ (up to $18 \%$ ) than the ENMs 9 and 10. However, its $P I$ value $\left(82 \mathrm{~kg} / \mathrm{m}^{2} \mathrm{~h}\right)$ is 44 and $38 \%$ lower than that of the ENMs 9 and 10 (i.e. 147 and $133 \mathrm{~kg} / \mathrm{m}^{2} \mathrm{~h}$, respectively) (Fig. S6 in SI). This result elucidates the good performance of the treated-optimized PSU ENMs for MF applications.

The values of $F R_{W}$ obtained for all PSU ENMs ranged from 81.9 to $99 \%$, and are higher than those reported by Schäfer et al. [43] during MF of $20 \mathrm{mg} / \mathrm{L} \mathrm{HA}$ solution at $\mathrm{pH} 8(81 \%)$ and $5 \mathrm{mg} / \mathrm{L} \mathrm{HA}$ solution at pH $10(73 \%)$ with a MF commercial hydrophilic membrane (GVWP, $0.22 \mu \mathrm{m}$ pore size; Millipore). The reduction of the irreversible fouling factor of PSU ENMs is important to extend the membrane lifetime for filtration application. Different ways have been adopted to improve the $F R_{W}$ including surface modification of ENMs by interfacial polymerization (IP) technique $[33,50]$.

Compared to other ENMs with HPT used for filtration $[2,5,7,24,26,37,51,52]$, the total manufacturing time of PSU ENMs of the present study was shorter. For other reported membranes the electrospinning process took between 1 and $8 \mathrm{~h}$, up to 10 times longer than the electrospinning fabrication time $\left(t_{e}\right)$ used in this study ( $45 \mathrm{~min}$ ). In addition, the HPT times used for the treated-optimized PSU ENMs of the present study were $60-75 \mathrm{~min}$, up to 18 -fold shorter than the time (120-1080 $\mathrm{min}$ ) reported for other membranes.

\section{Conclusions}

Different HPTs were investigated to improve the filtration performance of PSU ENMs. The effects of the HPT temperature (i.e. 210, 220, $230^{\circ} \mathrm{C}$ ) and time (i.e. $45,60,75,90,120,150,180 \mathrm{~min}$ ) on their morphology and structure were studied systematically. It was observed that increasing either the HPT temperature or time resulted in a reduction of $\bar{d}_{f}$ along with an increase of both $\lambda_{w}^{-}$and the number of connections between nanofibers, which led to an improvement of the structural integrity of the membranes. A gradual decrease of $\varepsilon$ and $\theta_{w}$ values of the PSU ENMs was obtained when the HPT temperature or the HPT time was increased, which resulted in membranes with smoother surfaces. No connection points between nanofibers could be detected when the membranes were prepared at a low HPT temperature (ENMs $1-2\left(210^{\circ} \mathrm{C}\right)$ ) or for a short HPT time (ENMs $3(60 \mathrm{~min})$ and $8(45 \mathrm{~min})$ ).

The main effects of increasing either the HPT temperature or the HPT time on the filtration properties of the membranes were a reduction of the HA permeate flux and an improvement of the HA separation factor.

It was observed that the fouling evolution rate of the PSU ENMs prepared with higher HPTs (i.e. ENMs 10 and 11) was faster. Pore blockage occurred earlier $\left(t_{c}<30 \mathrm{~min}\right)$ in these membranes compared to those prepared with lower HPTs (i.e. ENMs 4 and 8), in which pore blockage took place during the first $125 \mathrm{~min}$ of the filtration process.

Similar morphological characteristics as well as filtration performance were observed for the membranes treated at $220^{\circ} \mathrm{C}$ and those treated at $230^{\circ} \mathrm{C}$ for half the heating time. Despite these similarities, the values of $\alpha_{f}$ of the membranes treated at $230{ }^{\circ} \mathrm{C}$ were up to $14.6 \%$ higher than those of the membranes treated at $220^{\circ} \mathrm{C}$, resulting in up to $16.4 \%$ better performance indexes. From these results it can be concluded that it is better to perform HPT at a higher temperature, because the reduction in HPT time permits energy and cost savings.

Compared to the best PSU ENMs (i.e. ENMs 9 and 10), lower PI value was obtained for the commercial PES MF membrane (HPWP, Millipore) tested under the same filtration procedure to that followed for the PSU ENMs. This confirms the good performance of the prepared PSU ENMs for MF applications.

The significantly higher PWP of PSU ENMs compared to commercial flat sheet filtration membranes allows the use of lower pressures and thus reduces energy consumption during filtration. Together with their short manufacturing time, this property makes PSU ENMs fabricated with the optimized HPT conditions very promising candidates to reduce the overall costs and energy consumption of MF applications.

\section{Acknowledgments}

The authors gratefully acknowledge the financial support of the Spanish Ministry of Economy and Competitiveness through its project CTM2015-65348-C2-2-R. P. Arribas is thankful to the Campus of International Excellence, Moncloa Campus (UCM-UPM), for the $\mathrm{PhD}$ grant.

\section{Appendix A. Supplementary material}

Supplementary data to this article can be found online at https:// doi.org/10.1016/j.seppur.2019.05.097. 


\section{References}

[1] Y. Huang, Q.L. Huang, H. Liu, C.X. Zhang, Y.W. You, N.N. Li, C.F. Xiao, Preparation, characterization, and applications of electrospun ultrafine fibrous PTFE porous membranes, J. Membr. Sci. 523 (2017) 317-326.

[2] R. Gopal, S. Kaur, Z. Ma, C. Chan, S. Ramakrishna, T. Matsuura, Electrospun nanofibrous filtration membrane, J. Membr. Sci. 281 (2006) 581-586.

[3] R. Gopal, S. Kaur, C.Y. Feng, C. Chan, S. Ramakrishna, S. Tabe, T. Matsuura, Electrospun nanofibrous polysulfone membranes as pre-filters: Particulate removal, J. Membr. Sci. 289 (2007) 210-219.

[4] J. Doshi, D.H. Reneker, Electrospinning process and applications of electrospun fibers, J. Electrostat. 35 (1995) 151-160.

[5] Z. Ma, M. Kotaki, S. Ramakrishna, Surface modified nonwoven polysulphone (PSU) fiber mesh by electrospinning: A novel affinity membrane, J. Membr. Sci. 272 (2006) 179-187.

[6] S.-S. Choi, Y.S. Lee, C.W. Joo, S.G. Lee, J.K. Park, K.-S. Han, Electrospun PVDF nanofiber web as polymer electrolyte or separator, Electrochim. Acta 50 (2004) 339-343.

[7] P. Arribas, M. Khayet, M.C. García-Payo, L. Gil, Self-sustained electro-spun polysulfone nano-fibrous membranes and their surface modification by interfacial polymerization for micro- and ultra-filtration, Sep. Purif. Technol. 138 (2014) $118-129$.

[8] Y. Liu, R. Wang, H. Ma, B.S. Hsiao, B. Chu, High-flux microfiltration filters based on electrospun polyvinylalcohol nanofibrous membranes, Polymer 54 (2013) 548-556.

[9] S. Homaeigohar, J. Koll, E.T. Lilleodden, M. Elbahri, The solvent induced interfiber adhesion and its influence on the mechanical and filtration properties of polyethersulfone electrospun nanofibrous microfiltration membranes, Sep. Purif. Technol. 98 (2012) 456-463.

[10] H.-C. Kim, B.G. Choi, J. Noh, K.G. Song, S.-H. Lee, S.K. Maeng, Electrospun nanofibrous PVDF-PMMA MF membrane in laboratory and pilot-scale study treating wastewater from Seoul Zoo, Desalination 346 (2014) 107-114.

[11] A. Baji, Y.-W. Mai, S.-C. Wong, M. Abtahi, P. Chen, Electrospinning of polymer nanofibers: Effects on oriented morphology, structures and tensile properties, Compos. Sci. Technol. 70 (2010) 703-718.

[12] W. Yuan, A.L. Zydney, Humic acid fouling during microfiltration, J. Membr. Sci. 157 (1999) 1-12.

[13] N. Yang, X. Wen, T.D. Waite, X. Wang, X. Huang, Natural organic matter fouling of microfiltration membranes: Prediction of constant flux behavior from constant pressure materials properties determination, J. Membr. Sci. 366 (2011) 192-202.

[14] R. Seifollahy Astaraee, T. Mohammadi, N. Kasiri, Analysis of BSA, dextran and humic acid fouling during microfiltration, experimental and modeling, Food Bioprod. Process. 94 (2015) 331-341.

[15] Y. Su, C. Li, W. Zhao, Q. Shi, H. Wang, Z. Jiang, S. Zhu, Modification of polyethersulfone ultrafiltration membranes with phosphorylcholine copolymer can remarkably improve the antifouling and permeation properties, J. Membr. Sci. 322 (2008) 171-177.

[16] A.-R. Cho, D.M. Shin, H.W. Jung, J.C. Hyun, J.S. Lee, D. Cho, Y.L. Joo, Effect of annealing on the crystallization and properties of electrospun polylatic acid and nylon 6 fibers, J. Appl. Polym. Sci. 120 (2011) 752-758.

[17] L. Huang, S.S. Manickam, J.R. McCutcheon, Increasing strength of electrospun nanofiber membranes for water filtration using solvent vapor, J. Membr. Sci. 436 (2013) 213-220.

[18] X. Ran, Z. Jia, C. Han, Y. Yang, L. Dong, Thermal and mechanical properties of blends of polylactide and poly(ethylene glycol-co-propylene glycol): Influence of annealing, J. Appl. Polym. Sci. 116 (2010) 2050-2057.

[19] H.-C. Chen, C.-H. Tsai, M.-C. Yang, Mechanical properties and biocompatibility of electrospun polylactide/poly(vinylidene fluoride) mats, J. Polym. Res. 18 (2011) 319-327.

[20] S. Kaur, R. Barhate, S. Sundarrajan, T. Matsuura, S. Ramakrishna, Hot pressing of electrospun membrane composite and its influence on separation performance on thin film composite nanofiltration membrane, Desalination 279 (2011) 201-209.

[21] B.S. Lalia, E. Guillen-Burrieza, H.A. Arafat, R. Hashaikeh, Fabrication and characterization of polyvinylidenefluoride-co-hexafluoropropylene (PVDF-HFP) electrospun membranes for direct contact membrane distillation, J. Membr. Sci. 428 (2013) 104-115.

[22] Y. Liao, R. Wang, M. Tian, C. Oiu, A.G. Fane, Fabrication of polyvinylidene fluoride (PVDF) nanofiber membranes by electro-spinning for direct contact membrane distillation, J. Membr. Sci. 425-426 (2013) 30-39.

[23] Y. You, S. Won Lee, S. Jin Lee, W.H. Park, Thermal interfiber bonding of electrospun poly(l-lactic acid) nanofibers, Mater. Lett. 60 (2006) 1331-1333.

[24] S.S. Homaeigohar, K. Buhr, K. Ebert, Polyethersulfone electrospun nanofibrous composite membrane for liquid filtration, J. Membr. Sci. 365 (2010) 68-77.

[25] Y. Liang, S. Cheng, J. Zhao, C. Zhang, S. Sun, N. Zhou, Y. Qiu, X. Zhang, Heat treatment of electrospun Polyvinylidene fluoride fibrous membrane separators for rechargeable lithium-ion batteries, J. Power Sources 240 (2013) 204-211.

[26] L. Li, R. Hashaikeh, H.A. Arafat, Development of eco-efficient micro-porous membranes via electrospinning and annealing of poly (lactic acid), J. Membr. Sci. 436 (2013) 57-67.

[27] S.S. Homaeigohar, H. Mahdavi, M. Elbahri, Extraordinarily water permeable sol-gel formed nanocomposite nanofibrous membranes, J. Colloid Interface Sci. 366 (2012) $51-56$.

[28] S.S. Homaeigohar, M. Elbahri, Novel compaction resistant and ductile nanocomposite nanofibrous microfiltration membranes, J. Colloid Interface Sci. 372 (2012) 6-15.

[29] Y. Liao, C.H. Loh, M. Tian, R. Wang, A.G. Fane, Progress in electrospun polymeric nanofibrous membranes for water treatment: Fabrication, modification and applications, Prog. Polym. Sci. 77 (2018) 69-94.

[30] C. Migliaresi, D. Cohn, A. De Lollis, L. Fambri, Dynamic mechanical and calorimetric analysis of compression-molded PLLA of different molecular weights: Effect of thermal treatments, J. Appl. Polym. Sci. 43 (1991) 83-95.

[31] D. Aussawasathien, C. Teerawattananon, A. Vongachariya, Separation of micron to sub-micron particles from water: Electrospun nylon-6 nanofibrous membranes as pre-filters, J. Membr. Sci. 315 (2008) 11-19.

[32] K. Smolders, A.C.M. Franken, Terminology for Membrane Distillation, Desalination 72 (1989) 249-262.

[33] M.N.A. Seman, M. Khayet, N. Hilal, Nanofiltration thin-film composite polyester polyethersulfone-based membranes prepared by interfacial polymerization, J. Membr. Sci. 348 (2010) 109-116.

[34] X. Yuan, Y. Zhang, C. Dong, J. Sheng, Morphology of ultrafine polysulfone fibers prepared by electrospinning, Polym. Int. 53 (2004) 1704-1710.

[35] L. Liu, Z. Pan, Properties of hydrophilic chitosan/polysulfone nanofibrous filtration membrane, J. Eng. Fiber. Fabr. 9 (2014) 76-86.

[36] D. Hussain, F. Loyal, A. Greiner, J.H. Wendorff, Structure property correlations for electrospun nanofiber nonwovens, Polymer 51 (2010) 3989-3997.

[37] M. Essalhi, M. Khayet, Self-sustained webs of polyvinylidene fluoride electrospun nanofibers at different electrospinning times: 1 . Desalination by direct contact membrane distillation, J. Membr. Sci. 433 (2013) 167-179.

[38] A. Marmur, Wetting on hydrophobic rough surfaces: to be heterogeneous or not to be? Langmuir 19 (2003) 8343-8348.

[39] B. Bhushan, Y. Chae Jung, Wetting study of patterned surfaces for superhydrophobicity, Ultramicroscopy 107 (2007) 1033-1041.

[40] H. Savoji, D. Rana, T. Matsuura, S. Tabe, C. Feng, Development of plasma and/or chemically induced graft co-polymerized electrospun poly(vinylidene fluoride) membranes for solute separation, Sep. Purif. Technol. 108 (2013) 196-204.

[41] S. Hong, M. Elimelech, Chemical and physical aspects of natural organic matter (NOM) fouling of nanofiltration membranes, J. Membr. Sci. 132 (1997) 159-181.

[42] C.-C. Ho, A.L. Zydney, A combined pore blockage and cake filtration model for protein fouling during microfiltration, J. Colloid Interface Sci. 232 (2000) 389-399.

[43] A.I. Schäfer, U. Schwicker, M.M. Fischer, A.G. Fane, T.D. Waite, Microfiltration of colloids and natural organic matter, J. Membr. Sci. 171 (2000) 151-172.

[44] W. Yuan, A. Kocic, A.L. Zydney, Analysis of humic acid fouling during microfiltration using a pore blockage-cake filtration model, J. Membr. Sci. 198 (2002) $51-62$.

[45] K. Xiao, Y. Shen, X. Huang, An analytical model for membrane fouling evolution associated with gel layer growth during constant pressure stirred dead-end filtration, J. Membr. Sci. 427 (2013) 139-149.

[46] K. Xiao, J. Sun, Y. Mo, Z. Fang, P. Liang, X. Huang, J. Ma, B. Ma, Effect of membrane pore morphology on microfiltration organic fouling: PTFE/PVDF blend membranes compared with PVDF membranes, Desalination 343 (2014) 217-225.

[47] J. Bae, I. Baek, H. Choi, Mechanically enhanced PES electrospun nanofiber membranes (ENMs) for microfiltration: The effects of ENM properties on membrane performance, Water Res. 105 (2016) 406-412.

[48] L. Marbelia, M. Mulier, D. Vandamme, K. Muylaert, A. Szymczyk, I.F.J. Vankelecom, Polyacrylonitrile membranes for microalgae filtration: Influence of porosity, surface charge and microalgae species on membrane fouling, Algal Res. 19 (2016) 128-137.

[49] X. Zhuang, L. Shi, K. Jia, B. Cheng, W. Kang, Solution blown nanofibrous membrane for microfiltration, J. Membr. Sci. 429 (2013) 66-70.

[50] M.N. Abu Seman, M. Khayet, N. Hilal, Development of antifouling properties and performance of nanofiltration membranes modified by interfacial polymerisation, Desalination 273 (2011) 36-47.

[51] A.M. Bazargan, M. Keyanpour-rad, F.A. Hesari, M.E. Ganji, A study on the microfiltration behavior of self-supporting electrospun nanofibrous membrane in water using an optical particle counter, Desalination 265 (2011) 148-152.

[52] S. Kaur, Z. Ma, R. Gopal, G. Singh, S. Ramakrishna, T. Matsuura, Plasma-induced graft copolymerization of poly(methacrylic acid) on electrospun poly(vinylidene fluoride) nanofiber membrane, Langmuir 23 (2007) 13085-13092. 